\title{
TMT-Based Quantitative Proteomics Analysis of the Fish-Borne Spoiler Shewanella putrefaciens Subjected to Cold Stress Using LC-MS/MS
}

\author{
Xin Gao,,$^{1,2,3,4}$ Peiyun Li, ${ }^{1,2,3,4}$ Jun Mei $\mathbb{D}^{1},{ }^{1,2,3,4}$ and Jing Xie $\mathbb{C D}^{1,2,3,4,5}$ \\ ${ }^{1}$ College of Food Science and Technology, Shanghai Ocean University, Shanghai 201306, China \\ ${ }^{2}$ National Experimental Teaching Demonstration Center for Food Science and Engineering Shanghai Ocean University, \\ Shanghai 201306, China \\ ${ }^{3}$ Shanghai Engineering Research Center of Aquatic Product Processing and Preservation, Shanghai 201306, China \\ ${ }^{4}$ Shanghai Professional Technology Service Platform on Cold Chain Equipment Performance and Energy Saving Evaluation, \\ Shanghai 201306, China \\ ${ }^{5}$ School of Public Administration and Services, Shanghai Urban Construction Vocational College, Shanghai 201415, China
}

Correspondence should be addressed to Jun Mei; delightmay@hotmail.com and Jing Xie; jxie@shou.edu.cn

Received 29 August 2020; Revised 4 November 2020; Accepted 26 December 2020; Published 8 January 2021

Academic Editor: Ajaya Kumar Singh

Copyright ( 2021 Xin Gao et al. This is an open access article distributed under the Creative Commons Attribution License, which permits unrestricted use, distribution, and reproduction in any medium, provided the original work is properly cited.

\begin{abstract}
Shewanella putrefaciens is a specific spoilage bacterium for fish during cold storage. To better understand the molecular mechanisms of cold stress adaptation of S. putrefaciens, tandem mass tag- (TMT-) based quantitative proteomic analysis was performed to detect the effects of cold stress on protein expression profiles in S. putrefaciens which had been cultivated at $4^{\circ} \mathrm{C}$ and $30^{\circ} \mathrm{C}$, respectively. A total of 266670 peptide spectrum matching numbers were quantified proteins after data analysis. Of the 2292 proteins quantitatively analyzed, a total of 274 were found to be differentially expressed (DE) under cold stress compared with the nonstress control. By integrating the results of Kyoto Encyclopedia of Genes and Genomes (KEGG) analyses, 9 common KEGG terms were found notable for the cold-responsive proteins. Generally, the DE proteins involved in carbohydrate, amino acid, and fatty acid biosynthesis and metabolism were significantly upregulated, leading to a specific energy conservation survival mode. The DE proteins related to DNA repair, transcription, and translation were upregulated, implicating change of gene expression and more protein biosynthesis needed in response to cold stress.
\end{abstract}

\section{Introduction}

Fresh fish is very perishable due to endogenous enzymes and microbial activities, which can result in large economic losses [1]. Indeed, the intrinsic properties of fresh fish are favourable for growth and enzymatic activity of spoilage bacteria, with the consequent off-flavours, off-odours, discoloration, textural changes, and slime formation [2]. Cold storage is widely used to maintain the quality of fish and prolong the shelf life $[3,4]$. Shewanella putrefaciens is considered as the common specific spoilage organisms (SSOs) in fish during cold storage $[5,6]$. $S$. putrefaciens has been reported to be able to use electron acceptors, such as TMAO, instead of oxygen to survive under oxygen or hypoxia conditions. It can produce proteolytic and lipolytic enzymes broken down proteins and produce various flavour defects to lower the fish quality [7]. In addition, S. putrefaciens is a cold-adapted bacterium in refrigerated fish and exhibits many special characteristics and molecular mechanisms that allow them to adapt to the cold stress environment $[8,9]$.

Some bacteria show a variety of physiological adaptation mechanisms, in order to cope with cold stress, survive, and grow in the cold stress environment. The mechanism is as follows:

(i) Increased fluidity of cell membranes

(ii) The freezing point of the aqueous phase in the cytoplasm decreased 
(iii) Macromolecules with enhanced stability

(iv) Under the effects of cold shock and cold acclimation, the reaction protein of cells to temperature decreases

(v) Peroxidase, catalase, redox, and superoxide dismutase protect reactive oxygen species

(vi) Whether the catalytic efficiency is maintained under cold stress and under cold stress [10-14].

Proteomics can provide advanced information on microbial metabolism and mechanisms of adaption to the cold stress environment, and this knowledge could be useful to reveal the cold-adaptation mechanisms in S. putrefaciens. Proteomics techniques have been widely used in microbiology, among which two-dimensional electrophoresis and protein identification are commonly used [15]. Due to its high technical reproducibility, improved proteome coverage, and more confident peptide identification and quantification, proteome analysis based on the tandem mass tag (TMT) is suitable for analyzing the abundance of thousands of proteins in complex biological samples [16, 17]. Some research studies have been performed to determine the proteomics changes of bacteria under cold stress. For example, proteomics methods were used to investigate the quantitative proteomics of Edwardsiella tarda in the midexponential growth phase at the optimal temperature of $37^{\circ} \mathrm{C}$ for $24 \mathrm{~h}$ and then through the hatch at $4^{\circ} \mathrm{C}$ for two weeks without vibration. Several key proteins related to DNA synthesis and transcription were significantly upregulated [18]. Similar comprehensive studies for S. putrefaciens have yet to be carried out. To provide insight into potential mechanisms underlying the ability of $S$. putrefaciens to grow at a temperature of $4^{\circ} \mathrm{C}$, we investigated the whole proteome response of $S$. putrefaciens exposed to cold stress using mass spectrometry.

\section{Materials and Methods}

2.1. Bacterial Strain and Growth Conditions. Broth cultures of $S$ putrefaciens (ATCC 8071) were prepared as follows: $1 \mathrm{~mL}$ aliquots of logarithmic phase grown broth cultures were transferred to $250 \mathrm{~mL}$ Erlenmeyer flasks containing $100 \mathrm{~mL}$ medium. The flasks were incubated aerobically agitating at $200 \mathrm{rpm}$, at 30 and $0^{\circ} \mathrm{C}$, respectively, until an absorbance (OD600) of 0.4 was attained. Six independent replicates were collected for each sample. The cell pellets prepared by centrifugation of the bacterial culture were resuspended and washed three times with phosphate-buffered saline (PBS).

2.2. Protein Extraction and Quantification. The spoilage cells were resuspended in a $600 \mathrm{~L}$ lysis buffer and subjected to high-intensity probe ultrasound in a $200 \mathrm{w}$ ice bath (UP250 S sonicator, Scientz, Ningbo, China). The mixtures were centrifuged at $16000 \mathrm{~g}$ at $4^{\circ} \mathrm{C}$ for $5 \mathrm{~min}$. The supernatant was collected, and the protein concentration was quantified using the bicinchoninic acid method. $10 \mu \mathrm{g}$ protein samples were added to $5 \mathrm{X}$ loading buffer at a rate of $5: 1(\mathrm{~V} / \mathrm{V})$, and then, the mixture was put in the boiling water for $5 \mathrm{~min}$. The purity of proteins was determined by sodium dodecyl sulfate-polyacrylamide gel electrophoresis (SDS-PAGE) on the basis of Hou et al. [19].

\subsection{Protein Enzymatic Hydrolysis and Peptide Desalting.} $300 \mu \mathrm{g}$ of each sample and 0.1 M DTT were mixed together. The mixture was heated in the boiling water for $5 \mathrm{~min}$ and then cooled to room temperature. Then, $200 \mu \mathrm{L}$ UA buffer $(8 \mathrm{M}$ urea, $150 \mathrm{mM}$ Tris- $\mathrm{HCl}, \mathrm{pH} 8.0$ ) was added to the mixture, and the protein was collected by centrifugation with $10 \mathrm{kDa}$ ultrafiltration centrifuge tube at $12,000 \times g$ for $15 \mathrm{~min}$. This process was repeated twice. Subsequently, the protein was added with $100 \mu \mathrm{L}$ IAA (50 mM IAA in UA) and oscillated at $600 \mathrm{rpm}$ for $1 \mathrm{~min}$ and centrifuged at $12,000 \times g$ for $10 \mathrm{~min}$ at room temperature in dark. The protein was collected by centrifugation with $10 \mathrm{kDa}$ ultrafiltration centrifuge tube at $12,000 \times g$ for $15 \mathrm{~min}$, and this procedure was repeated twice.

2.4. TMT Labelling. Desalted peptides were reconstituted in $0.1 \% \mathrm{FA}$, and the concentration of peptide was determined with the total protein assay kit (BCA method, Nanjing Jiancheng Bioengineering Institute, Nanjing, China). Peptides were reconstituted in $50 \mathrm{mM}$ 2-hydroxyethyl ( $\mathrm{pH} 8.5$ ) and TMT zero reagent (Thermo Fisher, Waltham, USA) was added from stocks dissolved in $100 \%$ anhydrous ACN. The peptide-TMT mixture was incubated for $1 \mathrm{~h}$ at $25^{\circ} \mathrm{C}$ and $400 \mathrm{rpm}$, and the labelling reaction was stopped by the addition of either $5 \%$ hydroxylamine to a final concentration of $0.4 \%$ or $8 \mu \mathrm{L}$ of $1 \mathrm{M}$ Tris, $\mathrm{pH} 8.0$, and incubation for $15 \mathrm{~min}$ at $25^{\circ} \mathrm{C}$ and $400 \mathrm{rpm}$. Peptide solutions were acidified with $45 \%(\mathrm{v} / \mathrm{v})$ of $10 \% \mathrm{FA}$ in $10 \% \mathrm{ACN}$ prior to drying or directly frozen at $80^{\circ} \mathrm{C}$ and dried by vacuum centrifugation. For in-depth proteome analyses, peptides derived from Lys$\mathrm{C} /$ trypsin digests of luminal and basal PDX tumors were processed as described in Fang et al. [4] but following the optimized TMT labelling protocol.

Briefly, $300 \mu \mathrm{g}$ peptides were dissolved in $60 \mu \mathrm{L}$ of $50 \mathrm{mM}$ HEPES ( $\mathrm{pH} 8.5$ ), and the labelling reaction was started by the addition of $300 \mu \mathrm{g}$ TMT reagents $(15 \mu \mathrm{L}$ of $56.7 \mathrm{mM}(20 \mu \mathrm{g} / \mu \mathrm{L})$ TMT stocks). Samples were incubated for $1 \mathrm{~h}$ at $25^{\circ} \mathrm{C}$ and $1,000 \mathrm{rpm}$, and the labelling reaction was quenched using $5 \mu \mathrm{L}$ of $5 \%$ hydroxylamine $\left(15 \mathrm{~min} ; 25^{\circ} \mathrm{C} ; 1,000 \mathrm{rpm}\right)$. Peptide solutions were pooled, frozen at $80^{\circ} \mathrm{C}$, and dried by vacuum centrifugation. Subsequently, TMT-labelled samples were desalted using tC18, RP solid-phase extraction cartridges (Waters Corp.; wash solvent: $0.1 \%$ TFA; elution solvent: $0.1 \%$ $\mathrm{FA}$ in $50 \% \mathrm{ACN}$ ), frozen at $-80^{\circ} \mathrm{C}$, and dried by vacuum centrifugation. TMT-labelled peptides were fractionated via a high-pH reversed-phase column (PierceTM High-pH Reversed-Phase Peptide Fractionation Kit, Thermo Fisher). Peptides were pooled into 15 fractions. Enrichment was performed using Ni-nitrilotriacetic acid superflow agarose beads (Qiagen) loaded with iron (III) ions. Subsequently, phosphopeptides were desalted using self-packed StageTips (wash solvent: $0.1 \% \mathrm{FA}$; elution solvent: $0.1 \% \mathrm{FA}$ in $50 \% \mathrm{ACN}$ ), frozen at $80^{\circ} \mathrm{C}$, and dried by vacuum centrifugation. 
2.5. LC-MS/MS Measurements. Tryptic peptides for oneshot analyses were analyzed on an EASY-nLC 1200 (Thermo Scientific) coupled to a Q Exactive Plus mass spectrometer (Thermo Fisher Scientific). After reconstitution in $0.1 \% \mathrm{FA}$, an amount corresponding to $500 \mathrm{ng}$ peptides was injected. Peptides were separated on an analytical column (EASY column, $75 \mu \mathrm{m} \times 45 \mathrm{~cm}$, Thermo Fisher Scientific) applying a flow rate of $300 \mathrm{~nL} / \mathrm{min}$ and following elution program: $0-2$ min: from 5 to $8 \%$ solvent B $(0.1 \%$ formic acid $+98 \%$ acetonitrile); $2-42 \mathrm{~min}$ : from 8 to $23 \%$ solvent $\mathrm{B} ; 42-50 \mathrm{~min}$ : from 23 to $40 \%$ solvent B; $50-52$ min: from 40 to $100 \%$ solvent B; and 52-60 min: 100\% solvent B, respectively. Mass spectrometers were operated in data-dependent and positive ionization mode. On the Q Exactive Plus, MS1 spectra were recorded at a resolution of $70 \mathrm{k}$ using an automatic gain control (AGC) target value of $1 \mathrm{e} 6$ charges and maximum injection time (maxIT) of $50 \mathrm{~ms}$. After peptide fragmentation via higher energy collisional dissociation, MS2 spectra of up to 10 precursors were acquired at $17.5 \mathrm{k}$ resolution using an AGC target value of $1 \mathrm{e} 5$ and a maxIT of 50 .

2.6. Database Searching. MaxQuant: for peptide and TMT titration experiments, peptide identification and quantification were performed using MaxQuant (version 1.6.0.16) with its built-in search engine, Andromeda $(15,16)$. Tandem mass spectra were searched against UniProt-S. putrefaciens3949-20190409. fasta (3949 entries, downloaded on April 9, 2019).

\section{Results and Discussion}

3.1. Identification of Proteins by Quantitative Proteomics Analysis. The results of spectrometry in the present research included protein identification, peptide identification, protein quantification, and differential protein classification analysis. A total of 266670 peptide spectrum matching (PSM) numbers, 19483 unique peptides, and 2292 quantified proteins were obtained after data analysis.

The intensity histogram for each sample is shown in Figure 1(a). Figure 1(b) was the box plot of normalized density and represented the box plots of $\log 2$ protein intensity average for each sample.

\subsection{Identification of Proteins and Their Total and Differential} Abundances. TMT-based quantitative proteomic analysis was developed to identify, quantify, and statistically verify quantitative differences in protein abundance from S. putrefaciens grown at $4^{\circ} \mathrm{C}$ versus $30^{\circ} \mathrm{C}$. The use of this approach ensured that the quantitative differences recorded were reliable, irrespective of the magnitude of the quantitative differences, and provided a robust means of interpreting the biological relevance of the data. A total of six experiments were analyzed by LC-MS/MS. Of these proteins, 274 were significant $\mathrm{DE}$ proteins with abundances that changed $>1.5$-fold (cultivated at $30^{\circ} \mathrm{C} /$ cultivated at $4^{\circ} \mathrm{C}$ ) and $P$ values of $<0.05$. A total of 189 proteins were upregulated and 85 proteins were downregulated (red and green background colors, respectively, in Table 1).
3.3. Bioinformatics Analysis of DE Proteins Identified by TMT. The upregulated and downregulated DE proteins were annotated by Gene Ontology (GO) with Fisher's exact test to better understand the roles that these proteins may play in cold adaptation. The significantly upregulated and downregulated $\mathrm{DE}$ proteins were classified into three categories using GO terms: biological process (BP), cell component (CC), and molecular function (MF). The downregulated DE proteins were clustered into $50 \mathrm{BP}$ terms (the most representative term was "organic substance metabolic process"), 20 CC terms (the most representative term was "cell"), and $18 \mathrm{MF}$ terms (the most representative term was "binding"). Each of the first ten terms in BP, CC, and MF determined based on $P$ values is listed in Figure 2.

3.4. Categorization of Differentially Downregulated Ribosomal Proteins (RPs). Ribosomes are thought to act as sensors for the heat and cold shock response networks in bacteria and are involved as signals linking environmental stimulus (temperature) with the increased heat shock gene expression [20]. Numerous studies have shown that RPs have a strong functional role, especially in regulating protein synthesis and maintaining the stability of ribosomal complexes [21]. Among the quantified proteins, 44 RPs were identified including 2330 S RPs and 21 50S RPs. Of the 183 significant DE proteins, $31 \mathrm{RPs}$ were upregulated (14 30S and 17 50S, Figure 3 ) and 21 RPs were downregulated (6 30S and 1550 ). This result is consistent with the fact that RPs may be important for the correct assembly of rRNA under cold stress. All of these RPs had a significant score based on FC, and the very large number indicates that more RPs were likely downregulated in the cold stress environment.

3.5. Main Energy Source Metabolism Network Analysis. The metabolic network of the main energy sources was established, including the citrate cycle, glycolysis/gluconeogenesis, fatty acid degradation, and main amino acid (valine, leucine, and isoleucine) degradation, to reveal the energy change profiles of $S$. putrefaciens in cold temperature (Figure 4). Some of these energy change profiles contained several proteins, and the preferred upregulated proteins are shown. Overall, 13 proteins were identified and quantified in the constructed energy metabolism network. In total, 6 proteins $(46.15 \%)$ showed a downregulated trend $(\mathrm{FC}<1)$, including 2 tricarboxylic acid cycle, 3 fatty acid degradation, and 3 main amino acid. Fumarate hydratase class I (EC 4.2.1.2) and isovaleryl-CoA dehydrogenase (EC 1.3.8.4) were slightly upregulated $(1.2<\mathrm{FC}<1.5, P<0.05)$, and phosphoglycerate kinase (EC 2.7.2.3), enolase (EC 4.2.1.11), malate dehydrogenase (EC 1.1.1.37), aconitate hydratase B (EC 4.2.1.3), and acetyl-CoA acetyltransferase (EC 2.3.1.9) were significantly upregulated ( $\mathrm{FC} \geq 1.5, P<0.05$ ). In addition, these two enzymes are involved in other metabolic processes, such as fatty acid degradation and degradation of valine, leucine, and isoleucine. In addition, retinal dehydrogenase 1 and 3-ketoacyl coenzyme A thiolase are also involved in the degradation of fatty acids and metabolic processes such as valine, leucine, and isoleucine [22]. In 


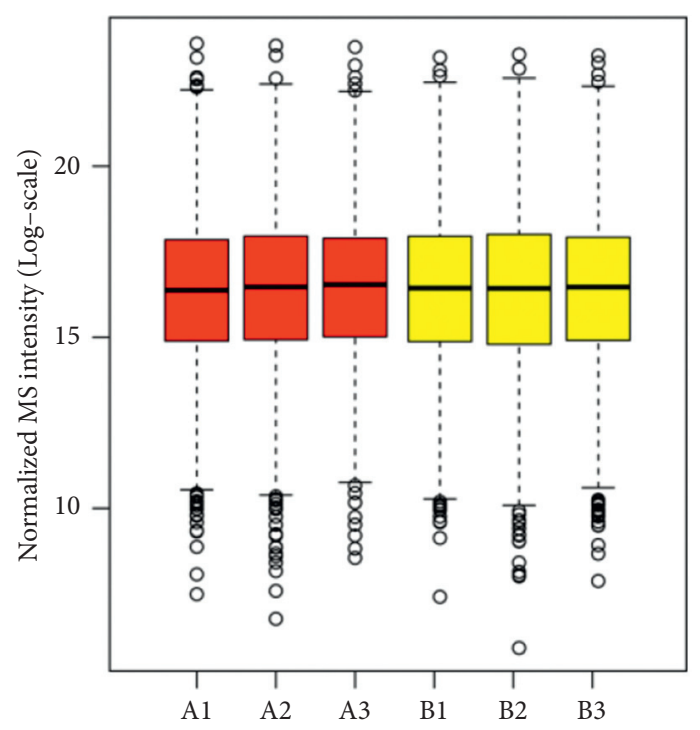

(a)
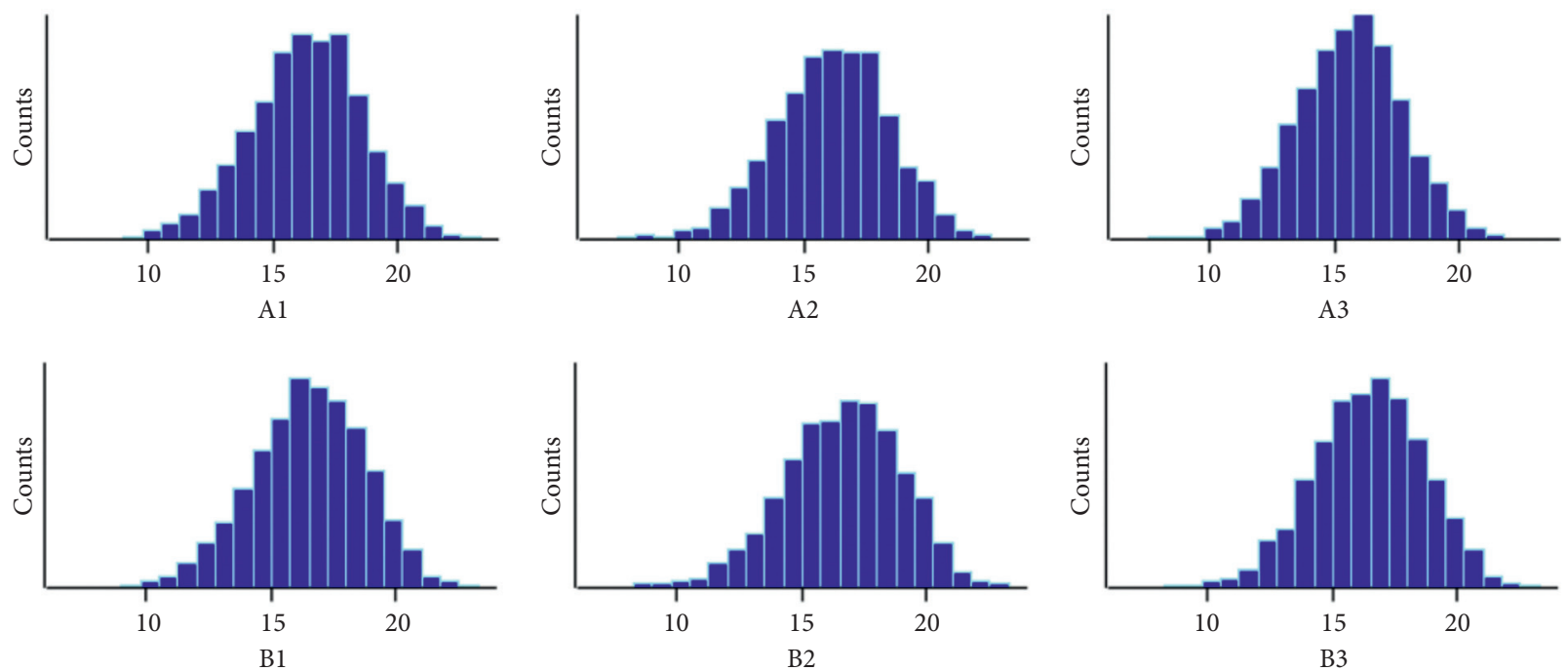

(b)

FIGURE 1: (a) Histogram of $\log 2$ protein intensity for each sample. (b) Box plots of log2 protein (or reporter ion) intensity average for each sample.

summary, amino acid and fatty acid degradation were decreased while glycolysis/gluconeogenesis was activated in S. putrefaciens under cold stress.

3.6. Interaction Network of Upregulated DE Proteins. Studies have shown that proteins in living cells do not exist as a single entity, but rather as functional associations within the cell [23]. It was of great significance to reveal the qualitative characteristics of proteins through the interaction between the formations of the network [24]. By using Cytoscape software against the $S$. oneidensis database, we explored protein interaction networks altered in the cold stress of $S$. putrefaciens by extracting a putative PPI network. According to the filter criteria of score $>400,23$ proteins in PPIs showed significantly differential abundance between
S. putrefaciens cultivated at $4^{\circ} \mathrm{C}$ and $30^{\circ} \mathrm{C}$ (Figure 5). The proteins were mainly associated with the cellular metabolic process, organonitrogen compound biosynthetic process, plasma membrane ATP synthesis coupled proton transport, protein metabolic process, ATP synthesis coupled proton transport, and ATP biosynthetic process. Among these proteins, 30S and 50S RPs were upregulated, including those encoded by rpl and rps. Proteins linked to ATP synthase, such as atpA and atpG, were downregulated significantly. We speculated that these proteins had a pivotal role in the network.

Bacteria may encounter a variety of physiological threats under low temperature stress, such as less and less membrane fluidity, less and less enzyme activity, irregular protein folding, lower and lower ice formation and transcription rate in cells, nutrient transport, translation, cell changes, and 
TABLE 1: Detailed information regarding upregulated and downregulated differentially expressed proteins in S. putrefaciens cultivated at $4^{\circ} \mathrm{C}$ and $30^{\circ} \mathrm{C}$.

\begin{tabular}{|c|c|c|c|c|c|}
\hline Accession $^{1}$ & $\begin{array}{l}\text { Sequence } \\
\text { length }\end{array}$ & $\mathrm{FC}^{2}$ & $\begin{array}{c}\text { Gene } \\
\text { names }\end{array}$ & Locus & Protein names \\
\hline \multicolumn{6}{|c|}{$\begin{array}{l}\text { Amino acid transport and } \\
\text { metabolism }\end{array}$} \\
\hline A4Y849 & 505 & 0.52 & & Sputcn32_2411 & L-Lysine 6-monooxygenase, EC 1.14.13.59 \\
\hline A4Y315 & 797 & 0.61 & & Sputcn32_0617 & $\begin{array}{l}\text { Bifunctional aspartokinase/homoserine dehydrogenase } \\
\text { (includes aspartokinase, EC 2.7.2.4; homoserine dehydrogenase, } \\
\text { EC 1.1.1.3) }\end{array}$ \\
\hline A4Y550 & 456 & 0.70 & & Sputcn32_1355 & Zinc metalloprotease, EC 3.4.24.- \\
\hline A4Y4D8 & 451 & 0.72 & & Sputcn32_1093 & L-Glutamine synthetase, EC 6.3.1.2 \\
\hline A4YC19 & 582 & 0.80 & & Sputcn32_3795 & Urocanate reductase, EC 1.3.99.33 \\
\hline A4Y7I3 & 1614 & 0.82 & & Sputcn32_2195 & Glutamate dehydrogenase, EC 1.4.1.2 \\
\hline A4Y7Q7 & 939 & 1.20 & & Sputcn32_2269 & 2-Oxoglutarate dehydrogenase E1 component, EC 1.2.4.2 \\
\hline A4Y4E5 & 425 & 1.22 & & Sputcn32_1100 & 4-Aminobutyrate aminotransferase, EC 2.6.1.19 \\
\hline A4Y656 & 234 & 1.28 & & Sputcn32_1714 & 3-Oxoacid CoA-transferase, A subunit, EC 2.8.3.5 \\
\hline A4Y1J0 & 679 & 1.31 & & Sputcn32_0087 & Oligopeptidase A, EC 3.4.24.70 \\
\hline A4Y3F6 & 358 & 1.32 & alr & Sputcn32_0759 & Alanine racemase, EC 5.1.1.1 \\
\hline A4Y661 & 389 & 1.35 & & Sputcn32_1719 & Isovaleryl-CoA dehydrogenase, EC 1.3.8.4 \\
\hline A4Y4D3 & 285 & 1.39 & & Sputcn32_1088 & 3-Mercaptopyruvate sulfurtransferase, EC 2.8.1.2 \\
\hline A4Y657 & 315 & 1.42 & & Sputcn32_1715 & Hydroxymethylglutaryl-CoA lyase, EC 4.1.3.4 \\
\hline A4Y3U2 & 189 & 1.43 & & Sputcn32_0896 & Alkyl hydroperoxide reductase C, EC 1.11.1.15 \\
\hline A4Y2I9 & 524 & 1.44 & & Sputcn32_0440 & Histidine ammonia-lyase, EC 4.3.1.3 \\
\hline A4Y540 & 274 & 1.45 & dapD & Sputcn32_1345 & $\begin{array}{c}\text { 2,3,4,5-Tetrahydropyridine-2,6-dicarboxylate } \mathrm{N} \text { - } \\
\text { succinyltransferase, EC 2.3.1.117 }\end{array}$ \\
\hline A4Y542 & 278 & 1.45 & map & Sputcn32_1347 & Methionine aminopeptidase, EC 3.4.11.18 \\
\hline A4YBI5 & 377 & 1.46 & & Sputcn32_3610 & Alanine-glyoxylate aminotransferase, EC 2.6.1.44 \\
\hline A4Y342 & 405 & 1.46 & $\operatorname{argD}$ & Sputcn32_0645 & Acetylornithine aminotransferase, EC 2.6.1.11 \\
\hline A4YCC5 & 341 & 1.47 & tdh & Sputcn32_3902 & L-Threonine 3-dehydrogenase, EC 1.1.1.103 \\
\hline A4Y3C6 & 386 & 1.54 & & Sputcn32_0729 & Methionine gamma-lyase, EC 4.4.1.11 \\
\hline A4Y6M4 & 344 & 1.55 & astE & Sputcn32_1884 & Succinylglutamate desuccinylase, EC 3.5.1.96 \\
\hline A4YCC4 & 397 & 1.56 & $\mathrm{kbl}$ & Sputcn32_3901 & 2-Amino-3-ketobutyrate coenzyme A ligase, EC 2.3.1.29 \\
\hline A4Y7N9 & 444 & 1.61 & astB & Sputcn32_2251 & $\mathrm{N}$-succinylarginine dihydrolase, EC 3.5.3.23 \\
\hline $\mathrm{A} 4 \mathrm{Y} 1 \mathrm{I} 2$ & 555 & 1.82 & hutU & Sputcn32_0079 & Urocanate hydratase, EC 4.2.1.49 \\
\hline A4Y1I0 & 408 & 1.85 & hutI & Sputcn32_0077 & Imidazolonepropionase, EC 3.5.2.7 \\
\hline A4Y1I7 & 451 & 1.89 & & Sputcn32_0084 & NADPH-glutathione reductase, EC 1.8.1.7 \\
\hline A4Y596 & 300 & 1.89 & & Sputcn32_1402 & 3-Hydroxyisobutyrate dehydrogenase, EC 1.1.1.31 \\
\hline A4YAE0 & 364 & 1.93 & gcvT & Sputcn32_3211 & Aminomethyltransferase, EC 2.1.2.10 \\
\hline A4Y612 & 346 & 2.05 & & Sputcn32_1670 & 4-Hydroxyphenylpyruvate dioxygenase, EC 1.13.11.27 \\
\hline A4Y659 & 288 & 2.09 & & Sputcn32_1717 & Methylglutaconyl-CoA hydratase, EC 4.2.1.18 \\
\hline A4Y8W2 & 197 & 2.18 & & Sputcn32_2676 & Thiol peroxidase, EC 1.11.1.15 \\
\hline A4Y946 & 370 & 2.20 & aguA & Sputcn32_2760 & Putative agmatine deiminase, EC 3.5.3.12 \\
\hline A4Y3Y4 & 169 & 2.21 & $\operatorname{luxS}$ & Sputcn32_0938 & S-Ribosylhomocysteine lyase, EC 4.4.1.21 \\
\hline A4Y733 & 396 & 2.26 & & Sputcn32_2045 & Aminotransferase, EC 2.6.1.- \\
\hline A4YAD9 & 129 & 2.31 & gcvH & Sputcn32_3210 & Glycine cleavage system $\mathrm{H}$ protein \\
\hline
\end{tabular}

Carbohydrate transport

and metabolism

$\begin{array}{lllll}\text { A4Y4N4 } & 707 & 0.66 & & \text { Sputcn32_1189 } \\ \text { A4Y7R1 } & 131 & 0.67 & & \text { Sputcn32_2273 } \\ \text { A4Y9V1 } & 594 & 0.80 & \text { opgD } & \text { Sputcn32_3021 } \\ \text { A4Y493 } & 545 & \mathbf{1 . 3 2} & \text { pgi } & \text { Sputcn32_1048 } \\ \text { A4Y6B4 } & 164 & \mathbf{1 . 4 1} & & \text { Sputcn32_1772 } \\ \text { A4Y9A6 } & 404 & \mathbf{1 . 4 3} & \text { deoB } & \text { Sputcn32_2820 } \\ \text { A4Y566 } & 305 & \mathbf{1 . 4 9} & & \text { Sputcn32_1371 } \\ \text { A4Y6K9 } & 227 & \mathbf{1 . 5 3} & & \text { Sputcn32_1869 } \\ \text { A4Y579 } & 302 & \mathbf{1 . 6 0} & & \text { Sputcn32_1385 } \\ \text { A4Y769 } & 544 & \mathbf{1 . 7 6} & \text { opgG } & \text { Sputcn32_2081 }\end{array}$

Aldehyde ferredoxin oxidoreductase, EC 1.2.7.5

Succinate dehydrogenase subunit C, EC 1.3.5.1 Glucans biosynthesis protein D

Glucose-6-phosphate isomerase, EC 5.3.1.9

4-Hydroxy-4-methyl-2-oxoglutarate aldolase, EC 4.1.1.112 Phosphopentomutase, EC 5.4.2.7

$\mathrm{N}$-Acetylglucosamine kinase, EC 2.7.1.59

2-Keto-3-deoxy-phosphogluconate aldolase, EC 4.1.2.14

UTP--glucose-1-phosphate uridylyltransferase, EC 2.7.7.9 Glucans biosynthesis protein $\mathrm{G}$

Cell cycle control, cell

division, chromosome partitioning

A4Y3E0 
TABle 1: Continued.

\begin{tabular}{|c|c|c|c|c|c|}
\hline Accession $^{1}$ & $\begin{array}{l}\text { Sequence } \\
\text { length }\end{array}$ & $\mathrm{FC}^{2}$ & $\begin{array}{c}\text { Gene } \\
\text { names }\end{array}$ & Locus & Protein names \\
\hline \multicolumn{6}{|c|}{$\begin{array}{l}\text { Cell wall/membrane/ } \\
\text { envelope biogenesis }\end{array}$} \\
\hline A4Y6J0 & 192 & 0.59 & rnfA & Sputcn32_1850 & Ion-translocating oxidoreductase complex subunit A, EC 7.-.-.- \\
\hline A4YBG8 & 460 & 0.59 & & Sputcn32_3593 & Membrane fusion protein (MFP) family protein \\
\hline A4Y5V0 & 178 & 0.61 & pal & Sputcn32_1608 & Peptidoglycan-associated protein \\
\hline A 4 Y 2 N5 & 403 & 0.69 & $\mathrm{ftsW}$ & Sputcn32_0486 & Probable peptidoglycan glycosyltransferase FtsW, EC 2.4.1.129 \\
\hline A4YB04 & 244 & 0.70 & zapD & Sputcn32_3427 & Cell division protein ZapD \\
\hline A4Y378 & 330 & 0.71 & & Sputcn32_0681 & $\mathrm{Mg} 2+$ transporter protein, CorA family protein \\
\hline A4Y3B5 & 186 & 0.75 & lptC & Sputcn32_0718 & Lipopolysaccharide export system protein LptC \\
\hline A4Y8T7 & 395 & 0.77 & bamB & Sputcn32_2649 & Outer-membrane protein assembly factor BamB \\
\hline A4Y3B6 & 183 & 1.72 & & Sputcn32_0719 & $\begin{array}{l}\text { 3-Deoxy-D-manno-octulosonate 8-phosphate phosphatase } \\
\text { KdsC, EC 3.1.3.45 }\end{array}$ \\
\hline A4YBR9 & 197 & 1.78 & gmhA & Sputcn32_3694 & Phosphoheptose isomerase, EC 5.3.1.28 \\
\hline
\end{tabular}

Energy production and conversion

\begin{tabular}{|c|c|c|c|c|c|}
\hline A4Y920 & 320 & 0.58 & thrB & Sputcn32_2734 & Homoserine kinase, EC 2.7.1.39 \\
\hline A4Y6S9 & 334 & 0.62 & ruvB & Sputcn32_1939 & $\begin{array}{l}\text { Holliday junction ATP-dependent DNA helicase RuvB, EC } \\
\text { 3.6.4.12 }\end{array}$ \\
\hline A4Y398 & 545 & 0.68 & $\begin{array}{l}\text { groL } \\
\text { groEL }\end{array}$ & Sputcn32_0701 & $60 \mathrm{kDa}$ chaperonin \\
\hline A4Y7T7 & 637 & 0.68 & htpG & Sputcn32_2299 & Chaperone protein HtpG \\
\hline A4YCH7 & 142 & 0.68 & atpC & Sputcn32_3955 & $\begin{array}{c}\text { ATP synthase epsilon chain (ATP synthase F1 sector epsilon } \\
\text { subunit) (F-ATPase epsilon subunit) }\end{array}$ \\
\hline A4YCH9 & 286 & 0.69 & atpG & Sputcn32_3957 & ATP synthase gamma chain \\
\hline A4Y6J2 & 668 & 0.69 & uvrB & Sputcn32_1852 & UvrABC system protein $B$, protein UvrB \\
\hline A4Y3P6 & 410 & 0.69 & nqrB & Sputcn32_0850 & $\begin{array}{l}\mathrm{Na}(+) \text {-translocating NADH-quinone reductase subunit } \mathrm{B}, \mathrm{Na} \\
(+) \text {-NQR subunit } \mathrm{B}, \mathrm{Na}(+) \text {-translocating NQR subunit } \mathrm{B}, \mathrm{EC} \\
7.2 .1 .1\end{array}$ \\
\hline $\mathrm{A} 4 \mathrm{Y} 2 \mathrm{C} 0$ & 470 & 0.70 & ntrC & Sputcn32_0371 & DNA-binding transcriptional regulator $\mathrm{NtrC}$ \\
\hline $\mathrm{A} 4 \mathrm{Y} 4 \mathrm{~K} 2$ & 596 & 0.70 & lepA & Sputcn32_1157 & Elongation factor 4, EF-4, EC 3.6.5.n1 \\
\hline A4YBH4 & 670 & 0.73 & rep & Sputcn32_3599 & ATP-dependent DNA helicase Rep, EC 3.6.4.12 \\
\hline A4YAH6 & 604 & 0.73 & dsbD & Sputcn32_3247 & Thiol:disulfide interchange protein DsbD, EC 1.8.1.8 \\
\hline A4Y3F5 & 468 & 0.74 & & Sputcn32_0758 & Replicative DNA helicase, EC 3.6.4.12 \\
\hline A4YCH8 & 463 & 0.75 & atpD & Sputcn32_3956 & ATP synthase subunit beta, EC 7.1.2.2 \\
\hline A4YAV2 & 722 & 0.75 & & Sputcn32_3373 & DNA helicase, EC 3.6.4.12 \\
\hline A4Y1A4 & 461 & 0.76 & dnaA & Sputcn32_0001 & Chromosomal replication initiator protein DnaA \\
\hline A4Y934 & 856 & 0.76 & mutS & Sputcn32_2748 & DNA mismatch repair protein MutS \\
\hline A4YCI0 & 513 & 0.76 & atpA & Sputcn32_3958 & ATP synthase subunit alpha, EC 7.1.2.2 \\
\hline A4Y4B7 & 429 & 0.76 & & Sputcn32_1072 & NADH dehydrogenase, EC 1.6.99.3 \\
\hline A4Y 675 & 720 & 0.77 & ppk & Sputcn32_1733 & Polyphosphate kinase, EC 2.7.4.1 \\
\hline A4Y965 & 149 & 0.77 & nrdR & Sputcn32_2779 & Transcriptional repressor NrdR \\
\hline A4YBZ9 & 319 & 0.77 & birA & Sputcn32_3775 & Bifunctional ligase/repressor BirA \\
\hline A4Y406 & 274 & 0.78 & $\mathrm{hmuV}$ & Sputcn32_0960 & Hemin import ATP-binding protein $\mathrm{HmuV}$, EC 7.6.2.- \\
\hline A4Y9Z6 & 494 & 0.78 & & Sputcn32_3066 & $\mathrm{NAD}(\mathrm{P})$ transhydrogenase subunit beta, EC 7.1.1.1 \\
\hline A4Y3M4 & 464 & 0.79 & $\mathrm{mpl}$ & Sputcn32_0827 & $\begin{array}{l}\text { UDP-N-acetylmuramate--L-alanyl-gamma-D-glutamyl-meso- } \\
\text { 2,6-diaminoheptandioate ligase, EC 6.3.2.45 }\end{array}$ \\
\hline A4Y9A0 & 454 & 0.79 & $\operatorname{radA}$ & Sputcn32_2814 & DNA repair protein $\mathrm{RadA}$ \\
\hline A4Y2J9 & 696 & 0.80 & recG & Sputcn32_0450 & ATP-dependent DNA helicase RecG, EC 3.6.4.12 \\
\hline $\mathrm{A} 4 \mathrm{Y} 470$ & 857 & 0.80 & clpB & Sputcn32_1024 & Chaperone protein $\mathrm{ClpB}$ \\
\hline A4Y8E4 & 192 & 0.80 & tdk & Sputcn32_2506 & Thymidine kinase, EC 2.7.1.21 \\
\hline A4Y9N9 & 207 & 0.81 & & Sputcn32_2957 & Corrinoid adenosyltransferase, EC 2.5.1.17 \\
\hline A4Y5P9 & 602 & 0.81 & $\mathrm{msbA}$ & Sputcn32_1557 & Lipid A export ATP-binding/permease protein MsbA, EC 7.5.2.6 \\
\hline A4Y427 & 388 & 0.82 & obg & Sputcn32_0981 & GTPase Obg, EC 3.6.5.- \\
\hline A4Y4E0 & 378 & 0.83 & potA & Sputcn32_1095 & $\begin{array}{c}\text { Spermidine/putrescine import ATP-binding protein PotA, EC } \\
7.6 .2 .11\end{array}$ \\
\hline A4Y8T3 & 525 & 1.20 & guaA & Sputcn32_2645 & GMP synthase (glutamine-hydrolyzing), EC 6.3.5.2 \\
\hline A4YBZ8 & 316 & 1.21 & coaA & Sputcn32_3774 & Pantothenate kinase, EC 2.7.1.33 \\
\hline A4Y8F6 & 571 & 1.22 & pros & Sputcn32_2518 & Proline--tRNA ligase, EC 6.1.1.15 \\
\hline A4Y9M1 & 1074 & 1.22 & carB & Sputcn32_2939 & Carbamoyl-phosphate synthase large chain, EC 6.3.5.5 \\
\hline
\end{tabular}


TABle 1: Continued.

\begin{tabular}{|c|c|c|c|c|c|}
\hline Accession $^{1}$ & $\begin{array}{l}\text { Sequence } \\
\text { length }\end{array}$ & $\mathrm{FC}^{2}$ & $\begin{array}{c}\text { Gene } \\
\text { names }\end{array}$ & Locus & Protein names \\
\hline A4Y5H4 & 556 & 1.24 & $\operatorname{gln} S$ & Sputcn32_1482 & Glutamine--tRNA ligase, EC 6.1.1.18 \\
\hline A4Y334 & 640 & 1.25 & deaD & Sputcn32_0637 & ATP-dependent RNA helicase DeaD, EC 3.6.4.13 \\
\hline A4YBS3 & 332 & 1.25 & $\operatorname{trpS}$ & Sputcn32_3698 & Tryptophan--tRNA ligase, EC 6.1.1.2 \\
\hline A4Y7N1 & 789 & 1.25 & & Sputcn32_2243 & Phosphoenolpyruvate synthase, EC 2.7.9.2 \\
\hline A4Y9M2 & 386 & 1.29 & $\operatorname{car} \mathrm{A}$ & Sputcn32_2940 & Carbamoyl-phosphate synthase small chain, EC 6.3.5.5 \\
\hline A4Y5T8 & 345 & 1.32 & purM & Sputcn32_1596 & Phosphoribosylformylglycinamidine cyclo-ligase, EC 6.3.3.1 \\
\hline A4Y6M8 & 360 & 1.33 & nadA & Sputcn32_1888 & Quinolinate synthase A, EC 2.5.1.72 \\
\hline A4Y545 & 245 & 1.34 & pyrH & Sputcn32_1350 & Uridylate kinase, EC 2.7 .4 .22 \\
\hline A4Y2N4 & 439 & 1.37 & murD & Sputcn32_0485 & UDP-N-acetylmuramoylalanine--D-glutamate ligase, EC 6.3.2.9 \\
\hline $\mathrm{A} 4 \mathrm{Y} 4 \mathrm{H} 3$ & 397 & 1.37 & tyrS & Sputcn32_1128 & Tyrosine--tRNA ligase, EC 6.1.1.1 \\
\hline A4YA38 & 550 & 1.37 & rhlE & Sputcn32_3108 & ATP-dependent RNA helicase RhlE, EC 3.6.4.13 \\
\hline A4Y928 & 958 & 1.38 & vals & Sputcn32_2742 & Valine--tRNA ligase, EC 6.1.1.9 \\
\hline A4Y9Z3 & 565 & 1.40 & cysI & Sputcn32_3063 & 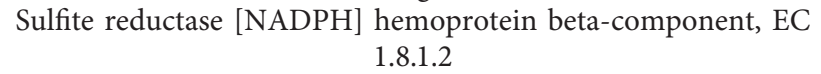 \\
\hline A4Y959 & 323 & 1.41 & thiL & Sputcn32_2773 & Thiamine-monophosphate kinase, EC 2.7.4.16 \\
\hline A4Y6G8 & 327 & 1.42 & pheS & Sputcn32_1828 & Phenylalanine--tRNA ligase alpha subunit, EC 6.1.1.20 \\
\hline A4Y7E3 & 231 & 1.43 & lolD & Sputcn32_2155 & $\begin{array}{c}\text { Lipoprotein-releasing system ATP-binding protein LolD, EC } \\
7.6 .2 .-\end{array}$ \\
\hline A4YBL9 & 292 & 1.44 & prpB & Sputcn32_3644 & 2-Methylisocitrate lyase, 2-MIC, EC 4.1.3.30 \\
\hline A4Y4A4 & 940 & 1.46 & iles & Sputcn32_1059 & Isoleucine--tRNA ligase, EC 6.1.1.5 \\
\hline A4Y5I7 & 401 & 1.49 & fabV & Sputcn32_1495 & Enoyl-[acyl-carrier-protein] reductase [NADH], EC 1.3.1.9 \\
\hline A4YA91 & 317 & 1.51 & gshB & Sputcn32_3162 & Glutathione synthetase, EC 6.3.2.3 \\
\hline A4Y7C9 & 143 & 1.53 & ndk & Sputcn32_2141 & Nucleoside diphosphate kinase, EC 2.7.4.6 \\
\hline A4Y6Z5 & 428 & 1.55 & serS & Sputcn32_2007 & Serine--tRNA ligase, EC 6.1.1.11 \\
\hline A4Y9Q3 & 639 & 1.60 & $\operatorname{dnaK}$ & Sputcn32_2971 & Chaperone protein DnaK \\
\hline $\mathrm{A} 4 \mathrm{Y} 2 \mathrm{H} 2$ & 198 & 1.71 & azoR & Sputcn32_0423 & FMN-dependent NADH-azoreductase, EC 1.7.1.17 \\
\hline A4YAY0 & 432 & 2.11 & purD & Sputcn32_3402 & Phosphoribosylamine--glycine ligase, EC 6.3.4.13 \\
\hline A4Y3S0 & 391 & 2.25 & pgk & Sputcn32_0874 & Phosphoglycerate kinase, EC 2.7.2.3 \\
\hline A4Y397 & 96 & 3.88 & $\begin{array}{l}\text { groS } \\
\text { groES }\end{array}$ & Sputcn32_0700 & $10 \mathrm{kDa}$ chaperonin \\
\hline \multicolumn{6}{|c|}{$\begin{array}{l}\text { Lipid transport and } \\
\text { metabolism }\end{array}$} \\
\hline A4Y4F4 & 203 & 0.54 & plsY & Sputcn32_1109 & G3P acyltransferase, GPAT, EC 2.3.1.275 \\
\hline A4Y9G1 & 219 & 0.70 & lipB & Sputcn32_2875 & Octanoyltransferase, EC 2.3.1.181 \\
\hline A4Y 625 & 238 & 0.72 & fadR & Sputcn32_1683 & Fatty acid metabolism regulator protein \\
\hline A4Y898 & 436 & 0.72 & fadI & Sputcn32_2460 & 3-Ketoacyl-CoA thiolase, EC 2.3.1.16 \\
\hline A4Y553 & 341 & 0.75 & $\operatorname{lpxD}$ & Sputcn32_1358 & UDP-3-O-acylglucosamine $\mathrm{N}$-acyltransferase, EC 2.3.1.- \\
\hline A4Y5S4 & 248 & 1.22 & & Sputcn32_1582 & 3-Oxoacyl-[acyl-carrier-protein] reductase, EC 1.1.1.100 \\
\hline A4Y4D0 & 498 & 1.34 & & Sputcn32_1085 & Aldehyde dehydrogenase (acceptor), EC 1.2.5.2 \\
\hline A4Y7Z3 & 354 & 1.38 & $\mathrm{fabH}$ & Sputcn32_2355 & 3-Oxoacyl-[acyl-carrier-protein] synthase 3, EC 2.3.1.180 \\
\hline A4Y3G1 & 245 & 1.49 & & Sputcn32_0764 & Enoyl-CoA hydratase, EC 4.2.1.17 \\
\hline A4Y5S3 & 308 & 1.74 & & Sputcn32_1581 & Malonyl CoA-acyl carrier protein transacylase, EC 2.3.1.39 \\
\hline A4Y883 & 411 & 1.83 & & Sputcn32_2445 & 3-Oxoacyl-[acyl-carrier-protein] synthase I, EC 2.3.1.41 \\
\hline A4Y5X9 & 171 & 2.05 & fabA & Sputcn32_1637 & $\begin{array}{c}\text { 3-Hydroxydecanoyl-[acyl-carrier-protein] dehydratase, EC } \\
4.2 .1 .59\end{array}$ \\
\hline A4Y5S5 & 77 & 2.54 & acpP & Sputcn32_1583 & Acyl carrier protein, ACP \\
\hline \multicolumn{6}{|c|}{$\begin{array}{l}\text { Nucleotide transport and } \\
\text { metabolism }\end{array}$} \\
\hline A4Y951 & 735 & 0.64 & & Sputcn32_2765 & (P)ppGpp synthetase I, SpoT/RelA, EC 2.7.6.5 \\
\hline A4Y9S5 & 343 & 1.32 & pyrC & Sputcn32_2994 & Dihydroorotase, EC 3.5.2.3 \\
\hline A4Y5T9 & 208 & 1.33 & upp & Sputcn32_1597 & Uracil phosphoribosyltransferase, EC 2.4.2.9 \\
\hline A4Y7I2 & 339 & 1.37 & pyrD & Sputcn32_2194 & Dihydroorotate dehydrogenase, EC 1.3.5.2 \\
\hline A4YAX9 & 543 & 1.46 & purH & Sputcn32_3401 & $\begin{array}{c}\text { Bifunctional purine biosynthesis protein PurH (includes } \\
\text { phosphoribosylaminoimidazolecarboxamide formyltransferase, } \\
\text { EC 2.1.2.3 (AICAR transformylase); IMP cyclohydrolase, EC } \\
\text { 3.5.4.10 (ATIC)) }\end{array}$ \\
\hline A4Y8X8 & 205 & 1.49 & & Sputcn32_2692 & dITP/XTP pyrophosphatase, EC 3.6.1.66 \\
\hline A4Y9A7 & 443 & 1.54 & deoA & Sputcn32_2821 & Thymidine phosphorylase, EC 2.4.2.4 \\
\hline A4Y2U2 & 252 & 1.55 & & Sputcn32_0543 & Uridine phosphorylase, EC 2.4.2.3 \\
\hline
\end{tabular}


TABle 1: Continued.

\begin{tabular}{cccccc}
\hline Accession $^{1}$ & $\begin{array}{c}\text { Sequence } \\
\text { length }\end{array}$ & FC $^{2}$ & $\begin{array}{c}\text { Gene } \\
\text { names }\end{array}$ & Locus & Protein names \\
\hline A4YCD7 & 331 & $\mathbf{1 . 6 2}$ & add & Sputcn32_3914 & Adenosine deaminase, EC 3.5.4.4 \\
A4Y2C8 & 103 & $\mathbf{1 . 6 4}$ & ppnP & Sputcn32_0379 & Pyrimidine/purine nucleoside phosphorylase, EC 2.4.2.2 \\
A4Y5R0 & 296 & $\mathbf{1 . 7 1}$ & cdd & Sputcn32_1568 & Cytidine deaminase, EC 3.5.4.5 \\
A4Y7B5 & 245 & $\mathbf{1 . 8 0}$ & kdsB & Sputcn32_2127 & 8-Amino-3,8-dideoxy-manno-octulosonate cytidylyltransferase, \\
A4Y7K5 & 193 & $\mathbf{1 . 9 9}$ & dcd & Sputcn32_2217 & EC 2.7.7.90 \\
A4Y726 & 231 & $\mathbf{2 . 0 8}$ & pyrF & Sputcn32_2038 & Orotidine 5' -phosphate decarboxylase, EC 4.1.1.23 \\
A4Y4P9 & 145 & $\mathbf{2 . 9 7}$ & & Sputcn32_1204 & Cytosine deaminase, EC 3.5.4.1 \\
\hline
\end{tabular}

Replication,

recombination, and

repair

\begin{tabular}{|c|c|c|c|c|}
\hline A4Y $6 \mathrm{I} 4$ & 213 & 0.74 & nth & Sputcn32_1844 \\
\hline A4Y5Y2 & 609 & 0.82 & uvrC & Sputcn32_1640 \\
\hline A4Y9F1 & 343 & 0.82 & & Sputcn32_2865 \\
\hline A4Y6M1 & 185 & 1.24 & seq $A$ & Sputcn32_1881 \\
\hline A4Y8J7 & 237 & 1.24 & fliA & Sputcn32_2559 \\
\hline A4Y729 & 95 & 1.43 & $\begin{array}{l}\text { ihfB } \\
\text { himD }\end{array}$ & Sputcn32_20 \\
\hline A4YBK6 & 92 & 1.63 & rpoZ & Sputcn32_3631 \\
\hline A4Y9D3 & 158 & 1.65 & greA & Sputcn32_2847 \\
\hline A4YB05 & 69 & 2.50 & yacG & Sputcn32_34 \\
\hline
\end{tabular}

Endonuclease III, EC 4.2.99.18

UvrABC system protein $C$, protein UvrC DNA polymerase III, delta subunit, EC 2.7.7.7 Negative modulator of initiation of replication RNA polymerase sigma factor FliA

Integration host factor subunit beta, IHF-beta

DNA-directed RNA polymerase subunit omega, EC 2.7.7.6

Transcription elongation factor GreA DNA gyrase inhibitor YacG

Secondary metabolites biosynthesis, transport, and catabolism

\begin{tabular}{|c|c|c|c|c|}
\hline A4YAT1 & 493 & 0.62 & ubiD & Sputcn32_3352 \\
\hline $\mathrm{A} 4 \mathrm{Y} 760$ & 222 & 0.64 & & Sputcn32_2072 \\
\hline A4Y3M6 & 176 & 0.69 & & Sputcn32_0829 \\
\hline A4Y930 & 418 & 0.71 & & Sputcn32_2744 \\
\hline A4YAL8 & 289 & 0.73 & psd & Sputcn32_3289 \\
\hline A4Y7Q6 & 400 & 0.74 & & Sputcn32_2268 \\
\hline A4Y9A3 & 331 & 0.75 & & Sputcn32_2817 \\
\hline A4Y7C7 & 164 & 0.76 & & Sputcn32_2139 \\
\hline A4Y719 & 437 & 0.79 & & Sputcn32_2031 \\
\hline A4Y9C6 & 277 & 0.82 & & Sputcn32_2840 \\
\hline A4Y2M0 & 522 & 1.21 & leuA & Sputcn32_0471 \\
\hline A4Y9M3 & 270 & 1.22 & dapB & Sputcn32_2941 \\
\hline A4Y9W8 & 173 & 1.27 & & Sputcn32_3038 \\
\hline $\mathrm{A} 4 \mathrm{Y} 2 \mathrm{M} 2$ & 474 & 1.29 & leuC & Sputcn32_0473 \\
\hline A4Y7E1 & 267 & 1.31 & & Sputcn32_2153 \\
\hline A4Y4A7 & 318 & 1.32 & ispH & Sputcn32_1062 \\
\hline A4Y4T4 & 440 & 1.34 & & Sputcn32_1239 \\
\hline A4Y3R8 & 664 & 1.35 & & Sputcn32_0872 \\
\hline A4YAZ4 & 888 & 1.39 & & Sputcn32_3417 \\
\hline A4YBI7 & 619 & 1.40 & ilvD & Sputcn32_3612 \\
\hline A4Y2M1 & 364 & 1.42 & leuB & Sputcn32_0472 \\
\hline A4Y486 & 163 & 1.44 & purE & Sputcn32_1041 \\
\hline A4Y6E8 & 514 & 1.48 & & Sputcn32_1807 \\
\hline $\mathrm{A} 4 \mathrm{Y} 4 \mathrm{X} 1$ & 293 & 1.49 & & Sputcn32_1276 \\
\hline A4Y5G2 & 394 & 1.49 & & Sputcn32_1470 \\
\hline A4Y424 & 331 & 1.51 & & Sputcn32_0978 \\
\hline A4Y7N3 & 357 & 1.54 & & Sputcn32_2245 \\
\hline A4Y591 & 396 & 1.55 & & Sputcn32_1397 \\
\hline A4YAY7 & 865 & 1.58 & & Sputcn32_3409 \\
\hline A4Y9W4 & 217 & 1.60 & & Sputcn32_3034 \\
\hline
\end{tabular}

3-Octaprenyl-4-hydroxybenzoate carboxy-lyase, EC 4.1.1.98 HAD-superfamily hydrolase, subfamily IA, variant 1, EC 3.1.3.18 Hypoxanthine phosphoribosyltransferase, EC 2.4.2.8 Aspartokinase, EC 2.7.2.4

Phosphatidylserine decarboxylase proenzyme, EC 4.1.1.65

(cleaved into phosphatidylserine decarboxylase alpha chain; phosphatidylserine decarboxylase beta chain)

Dihydrolipoyllysine-residue succinyltransferase component of

2-oxoglutarate dehydrogenase complex, EC 2.3.1.61 Phosphoserine phosphatase, EC 3.1.3.3

Acetolactate synthase, small subunit, EC 2.2.1.6

Phospholipase D/transphosphatidylase EC 2.7.8.8 Dihydropteroate synthase, EC 2.5.1.15 2-Isopropylmalate synthase, EC 2.3.3.13

4-Hydroxy-tetrahydrodipicolinate reductase, EC 1.17.1.8 Protoporphyrinogen oxidase, EC 1.3.3.4

3-Isopropylmalate dehydratase large subunit, EC 4.2.1.33 Inositol-1-monophosphatase, EC 3.1.3.25

4-Hydroxy-3-methylbut-2-enyl diphosphate reductase, EC 1.17.7.4

Isocitrate lyase, EC 4.1.3.1

Transketolase, EC 2.2.1.1

Pyruvate dehydrogenase E1 component, EC 1.2.4.1 Dihydroxy-acid dehydratase, EC 4.2.1.9

3-Isopropylmalate dehydrogenase, EC 1.1.1.85

N5-carboxyaminoimidazole ribonucleotide mutase, N5-CAIR mutase, EC 5.4.99.18

Fumarate hydratase class I, EC 4.2.1.2

Farnesyl-diphosphate synthase, EC 2.5.1.10 Glycerate kinase, EC 2.7.1.31

Trans-hexaprenyltranstransferase, EC 2.5.1.30

Phospho-2-dehydro-3-deoxyheptonate aldolase, EC 2.5.1.54 Acetyl-CoA acetyltransferase, EC 2.3.1.9

Aconitate hydratase B, EC 4.2.1.3

Dihydropteridine reductase, EC 1.5.1.34 
TABle 1: Continued.

\begin{tabular}{|c|c|c|c|c|c|}
\hline Accession $^{1}$ & $\begin{array}{l}\text { Sequence } \\
\text { length }\end{array}$ & $\mathrm{FC}^{2}$ & $\begin{array}{c}\text { Gene } \\
\text { names }\end{array}$ & Locus & Protein names \\
\hline A4Y670 & 288 & 1.63 & & Sputcn32_1728 & Acyl-CoA thioesterase II, EC 3.1.2.2 \\
\hline A4YAE8 & 311 & 1.66 & $\mathrm{mdh}$ & Sputcn32_3219 & Malate dehydrogenase, EC 1.1.1.37 \\
\hline A4Y494 & 318 & 1.66 & tal & Sputcn32_1049 & Transaldolase, EC 2.2.1.2 \\
\hline A4YAY4 & 354 & 1.68 & hemE & Sputcn32_3406 & Uroporphyrinogen decarboxylase, EC 4.1.1.37 \\
\hline A4Y5N5 & 203 & 1.74 & ribA & Sputcn32_1543 & GTP cyclohydrolase-2, EC 3.5.4.25 \\
\hline A4Y1D3 & 302 & 1.75 & hemF & Sputcn32_0030 & Oxygen-dependent coproporphyrinogen-III oxidase, EC 1.3.3.3 \\
\hline A4YBS4 & 226 & 1.75 & gph & Sputcn32_3699 & Phosphoglycolate phosphatase, EC 3.1.3.18 \\
\hline A4Y4G4 & 430 & 1.77 & hemL & Sputcn32_1119 & Glutamate-1-semialdehyde 2,1-aminomutase, EC 5.4.3.8 \\
\hline A4Y644 & 294 & 1.96 & dapA & Sputcn32_1702 & 4-Hydroxy-tetrahydrodipicolinate synthase, EC 4.3.3.7 \\
\hline A4Y846 & 278 & 2.00 & $\operatorname{trp} \mathrm{A}$ & Sputcn32_2408 & Tryptophan synthase alpha chain, EC 4.2.1.20 \\
\hline A4YBG2 & 310 & 2.04 & hemC & Sputcn32_3587 & Porphobilinogen deaminase, EC 2.5.1.61 \\
\hline A4Y7T5 & 214 & 2.14 & adk & Sputcn32_2297 & Adenylate kinase, EC 2.7.4.3 \\
\hline A4Y1E3 & 514 & 2.14 & gpmI & Sputcn32_0040 & $\begin{array}{l}\text { 2,3-Bisphosphoglycerate-independent phosphoglycerate mutase, } \\
\text { EC 5.4.2.12 }\end{array}$ \\
\hline A4Y881 & 338 & 2.14 & asd & Sputcn32_2443 & Aspartate-semialdehyde dehydrogenase, EC 1.2.1.11 \\
\hline A4Y9L3 & 220 & 2.15 & rpiA & Sputcn32_2931 & Ribose-5-phosphate isomerase A, EC 5.3.1.6 \\
\hline A4Y966 & 417 & 2.21 & glyA & Sputcn32_2780 & Serine hydroxymethyltransferase, SHMT, EC 2.1.2.1 \\
\hline A4Y3V1 & 597 & 2.22 & & Sputcn32_0905 & Fumarate reductase flavoprotein subunit, EC 1.3.5.4 \\
\hline A4Y452 & 292 & 2.27 & & Sputcn32_1006 & Cysteine synthase, EC 2.5.1.47 \\
\hline A4Y943 & 431 & 2.31 & eno & Sputcn32_2757 & Enolase, EC 4.2.1.11 \\
\hline A4Y7M6 & 344 & 2.41 & & Sputcn32_2238 & Leucine dehydrogenase, EC 1.4.1.9 \\
\hline \multicolumn{6}{|l|}{ Transcription } \\
\hline A4Y9B8 & 318 & 0.63 & $\operatorname{truB}$ & Sputcn32_2832 & tRNA pseudouridine synthase B, EC 5.4.99.25 \\
\hline A4Y9L4 & 396 & 0.79 & $\operatorname{rlmI}$ & Sputcn32_2932 & Ribosomal RNA large subunit methyltransferase I, EC 2.1.1.191 \\
\hline A4Y9C1 & 499 & 1.27 & nusA & Sputcn32_2835 & Transcription termination/antitermination protein NusA \\
\hline A4YB21 & 101 & 1.31 & fis & Sputcn32_3444 & DNA-binding protein Fis \\
\hline A 4 Y 2 K 5 & 237 & 1.31 & $\mathrm{rph}$ & Sputcn32_0456 & Ribonuclease PH, EC 2.7.7.56 \\
\hline A4Y960 & 134 & 1.66 & nusB & Sputcn32_2774 & Transcription antitermination protein NusB \\
\hline
\end{tabular}

Translation, ribosomal structure, and biogenesis A4Y5U6

A4Y7L6

A4YBZ6

A4YA83

A4Y1K1

A4YBY2

A4Y836

A4YCI2

A4YBX7

A4YCI4

A4Y8B9

$\mathrm{A} 4 \mathrm{Y} 8 \mathrm{C1}$

A4Y4K5

A4YBY4

A4Y4S7

A4YBV9

A4Y3E7

A4YBW 1

A4Y3E1

A4Y9C2

A4YBW4

A4Y544

A4YBW0

A4Y3E2

A4Y705

A4Y6A5

A4Y3F3

A4YBX9

\begin{tabular}{ccccc}
228 & 0.67 & tolQ & Sputcn32_1604 & Tol-Pal system protein TolQ \\
102 & 0.70 & clpS & Sputcn32_2228 & ATP-dependent Clp protease adapter protein ClpS \\
123 & 0.71 & secE & Sputcn32_3772 & Protein translocase subunit SecE \\
697 & 0.73 & fusA & Sputcn32_3154 & Elongation factor G, EF-G \\
281 & 0.73 & rlmJ & Sputcn32_0098 & Ribosomal RNA large subunit methyltransferase J, EC 2.1.1.266 \\
201 & 0.73 & rplD & Sputcn32_3758 & 50S ribosomal protein L4 \\
291 & 0.75 & & Sputcn32_2398 & Pseudouridine synthase, EC 5.4.99.- \\
156 & 0.76 & atpF & Sputcn32_3960 & ATP synthase subunit b \\
230 & 0.78 & rpsC & Sputcn32_3753 & 30S ribosomal protein S3 \\
273 & 0.78 & atpB & Sputcn32_3962 & ATP synthase subunit a \\
315 & 0.79 & secF & Sputcn32_2481 & Protein-export membrane protein SecF \\
110 & 0.79 & yajC & Sputcn32_2483 & Sec translocon accessory complex subunit YajC \\
338 & 0.80 & era & Sputcn32_1160 & GTPase Era \\
103 & $\mathbf{1 . 2 6}$ & rpsJ & Sputcn32_3760 & 30S ribosomal protein S10 \\
174 & $\mathbf{1 . 3 1}$ & bamE & Sputcn32_1232 & Outer-membrane protein assembly factor BamE \\
206 & $\mathbf{1 . 3 2}$ & rpsD & Sputcn32_3735 & 30S ribosomal protein S4 \\
246 & $\mathbf{1 . 3 3}$ & rlmB & Sputcn32_0750 & 23S rRNA (guanosine-2'-O-)-methyltransferase RlmB, EC \\
118 & $\mathbf{1 . 4 1}$ & rpsM & Sputcn32_3737 & 2.1.1.185 \\
142 & $\mathbf{1 . 4 2}$ & rplM & Sputcn32_0744 & 30S ribosomal protein S13 \\
151 & $\mathbf{1 . 4 2}$ & rimP & Sputcn32_2836 & 50S ribosomal protein L13 \\
144 & $\mathbf{1 . 4 4}$ & rplO & Sputcn32_3740 & Ribosome maturation factor RimP \\
283 & $\mathbf{1 . 4 5}$ & tsf & Sputcn32_1349 & 50S ribosomal protein L15 \\
130 & $\mathbf{1 . 4 7}$ & rpsK & Sputcn32_3736 & Elongation factor Ts, EF-Ts \\
130 & $\mathbf{1 . 4 9}$ & rpsI & Sputcn32_0745 & 30S ribosomal protein S11 \\
143 & $\mathbf{1 . 5 6}$ & infC & Sputcn32_2017 & 30S ribosomal protein S9 \\
85 & $\mathbf{1 . 5 7}$ & minE & Sputcn32_1763 & Translation initiation factor IF-3 \\
150 & $\mathbf{1 . 6 1}$ & rplI & Sputcn32_0756 & Cell division topological specificity factor \\
92 & $\mathbf{1 . 6 7}$ & rpsS & Sputcn32_3755 & 30S ribosomal protein L9 \\
& & & & 30S ribosomal protein S19 \\
\hline & &
\end{tabular}


TABLE 1: Continued.

\begin{tabular}{|c|c|c|c|c|c|}
\hline Accession $^{1}$ & $\begin{array}{c}\text { Sequence } \\
\text { length }\end{array}$ & $\mathrm{FC}^{2}$ & $\begin{array}{c}\text { Gene } \\
\text { names }\end{array}$ & Locus & Protein names \\
\hline A4YBY8 & 124 & 1.71 & rpsL & Sputcn32_3764 & 30 S ribosomal protein $\mathrm{S} 12$ \\
\hline A4YBV7 & 131 & 1.72 & rplQ & Sputcn32_3733 & 50S ribosomal protein L17 \\
\hline A4YBW5 & 60 & 1.72 & $\mathrm{rpmD}$ & Sputcn32_3741 & 50 S ribosomal protein L30 \\
\hline A4Y5S0 & 56 & 1.75 & $\mathrm{rpmF}$ & Sputcn32_1578 & 50 S ribosomal protein L32 \\
\hline A4Y9F3 & 109 & 1.77 & rsfS & Sputcn32_2867 & Ribosomal silencing factor RsfS \\
\hline A4Y9B7 & 89 & 1.84 & $\mathrm{rpsO}$ & Sputcn32_2831 & 30 S ribosomal protein $\mathrm{S} 15$ \\
\hline A4YBY7 & 156 & 1.86 & rpsG & Sputcn32_3763 & 30 S ribosomal protein $\mathrm{S} 7$ \\
\hline A4Y704 & 64 & 1.87 & $\mathrm{rpmI}$ & Sputcn32_2016 & 50 S ribosomal protein L35 \\
\hline A4Y7L4 & 72 & 1.90 & $\operatorname{infA}$ & Sputcn32_2226 & Translation initiation factor IF-1 \\
\hline A4Y426 & 84 & 1.90 & rpmA & Sputcn32_0980 & 50S ribosomal protein L27 \\
\hline A4Y4L3 & 83 & 1.90 & rpsP & Sputcn32_1168 & 30 S ribosomal protein S16 \\
\hline A4YBM9 & 73 & 1.92 & zapB & Sputcn32_3654 & Cell division protein ZapB \\
\hline A4YBX6 & 136 & 1.93 & rplP & Sputcn32_3752 & 50S ribosomal protein L16 \\
\hline A4Y6L5 & 186 & 1.96 & efp & Sputcn32_1875 & Elongation factor P, EF-P \\
\hline A4Y3F2 & 75 & 2.05 & rpsR & Sputcn32_0755 & 30 S ribosomal protein S18 \\
\hline $\mathrm{A} 4 \mathrm{Y} 4 \mathrm{~A} 1$ & 88 & 2.09 & rpsT & Sputcn32_1056 & 30 S ribosomal protein S20 \\
\hline A4Y5V1 & 249 & 2.09 & сроB & Sputcn32_1609 & Cell division coordinator $\mathrm{CpoB}$ \\
\hline A4Y6Z8 & 208 & 2.14 & lolA & Sputcn32_2010 & Outer-membrane lipoprotein carrier protein \\
\hline A4YB74 & 154 & 2.17 & $\operatorname{trmL}$ & Sputcn32_3498 & tRNA (cytidine (34)-2'-O)-methyltransferase, EC 2.1.1.207 \\
\hline A4YBX8 & 110 & 2.21 & $\mathrm{rplV}$ & Sputcn32_3754 & 50 S ribosomal protein L22 \\
\hline A4YBX2 & 104 & 2.22 & rplX & Sputcn32_3748 & 50 S ribosomal protein L24 \\
\hline $\mathrm{A} 4 \mathrm{Y} 2 \mathrm{~V} 2$ & 79 & 2.28 & $\mathrm{rpmE}$ & Sputcn32_0553 & 50 S ribosomal protein L31 \\
\hline A4Y546 & 185 & 2.28 & frr & Sputcn32_1351 & Ribosome-recycling factor, RRF \\
\hline A4YBW7 & 116 & 2.44 & rplR & Sputcn32_3743 & 50S ribosomal protein L18 \\
\hline A4YBX0 & 101 & 2.61 & $\operatorname{rpsN}$ & Sputcn32_3746 & 30 S ribosomal protein S14 \\
\hline A4Y703 & 118 & 2.62 & rplT & Sputcn32_2015 & 50 S ribosomal protein L20 \\
\hline A4Y2L3 & 57 & 3.30 & rpmG & Sputcn32_0464 & 50 S ribosomal protein L33 \\
\hline A4Y5X8 & 58 & 3.61 & $\mathrm{rmf}$ & Sputcn32_1636 & Ribosome modulation factor, RMF \\
\hline A4YCM5 & 45 & 3.83 & $\mathrm{rpmH}$ & Sputcn32_4005 & 50 S ribosomal protein L34 \\
\hline A4YBW2 & 37 & 4.44 & rpmJ & Sputcn32_3738 & 50 S ribosomal protein L36 \\
\hline \multicolumn{6}{|l|}{ Not assigned } \\
\hline A4Y655 & 218 & 1.41 & & Sputcn32_1713 & Butyryl-CoA:acetate CoA transferase, EC 2.8.3.8 \\
\hline
\end{tabular}

${ }^{1}$ UniProt and NCBI database accession numbers. ${ }^{2}$ Average ratio from three replicates by TMT experiment. A protein species was considered differentially accumulated if it exhibited a fold change $>1.5$-fold (cultivated at $4^{\circ} \mathrm{C} /$ cultivated at $30^{\circ} \mathrm{C}$ ) with a $P$ value of $<0.05$.

even division $[25,26]$. To overcome these challenges, bacteria employ several cold-adaptation strategies such as ensuring nutrient uptake, maintaining the integrity of membrane structure, retaining ribosome functionality, and facing inefficient, slowing protein folding, decreasing the ability in DNA replication and transcription and in RNA translation [27, 28]. Moreover, cold stress affects the membrane fluidity, thus leading the cells to counteract by crafting their membrane lipid composition [26]. Furthermore, bacteria under cold stress protect their DNA, and superoxide dismutase (SOD) and catalase (CATALase) are produced in response to oxidative stress in lipids and proteins due to damage at low temperatures [29].

3.7. Energy Metabolism. We detected 6 downregulated proteins and 7 upregulated proteins related to energy metabolism. A significantly higher level of enzymes involved in glycolysis, which may suggest that $S$. putrefaciens under implicates the production of high energy intermediates, such as pyruvate (Figure 3). Upregulation of the key enzymes phosphoglycerate kinase and enolase showed similar results in glycolysis. Phosphoglycerate kinase is a housekeeping gene referred to carbon metabolism and energy production [26]. There are eight DE proteins participating in phosphoglycerate kinase (PGK, EC 2.7.2.3), glycolysis, and enolase, which were more abundant in S. putrefaciens cultivated at $4^{\circ} \mathrm{C}$ than that at $30^{\circ} \mathrm{C}$ (S. putrefaciens cultivated at $4^{\circ} \mathrm{C} / \mathrm{S}$. putrefaciens cultivated at $30^{\circ} \mathrm{C}>1.5$ ) (Figure 3 ). Glycolysis was a more active energy-producing pathway in S. putrefaciens cultivated at $4^{\circ} \mathrm{C}$ under nonfavorable temperature, which was also demonstrated by Sun et al. [30]. PGK is found in every domain and in almost all living organisms [31]. It is coded by pgk and PGK activity relates to the conversion of ADP + 3-phospho-d-glyceryl phosphate to ATP + 3-phospho-d-glycerate. PGK is one of the oldest "housekeeping" enzymes, which is found in the most ubiquitous three-carbon portion of the best studied and probably the most ancient metabolic pathway-glycolysis, the Embden-Meyerhof-Parnas cycle (fermentation). PGK activity is also present in several other biochemical processes (e.g., Calvin-Benson-Bassham $\mathrm{CO}_{2}$ fixation cycle = "CBB") and is often characterized as metabolically essential [32]. Enolase is a rich expression of cytoplasmic protein in many 


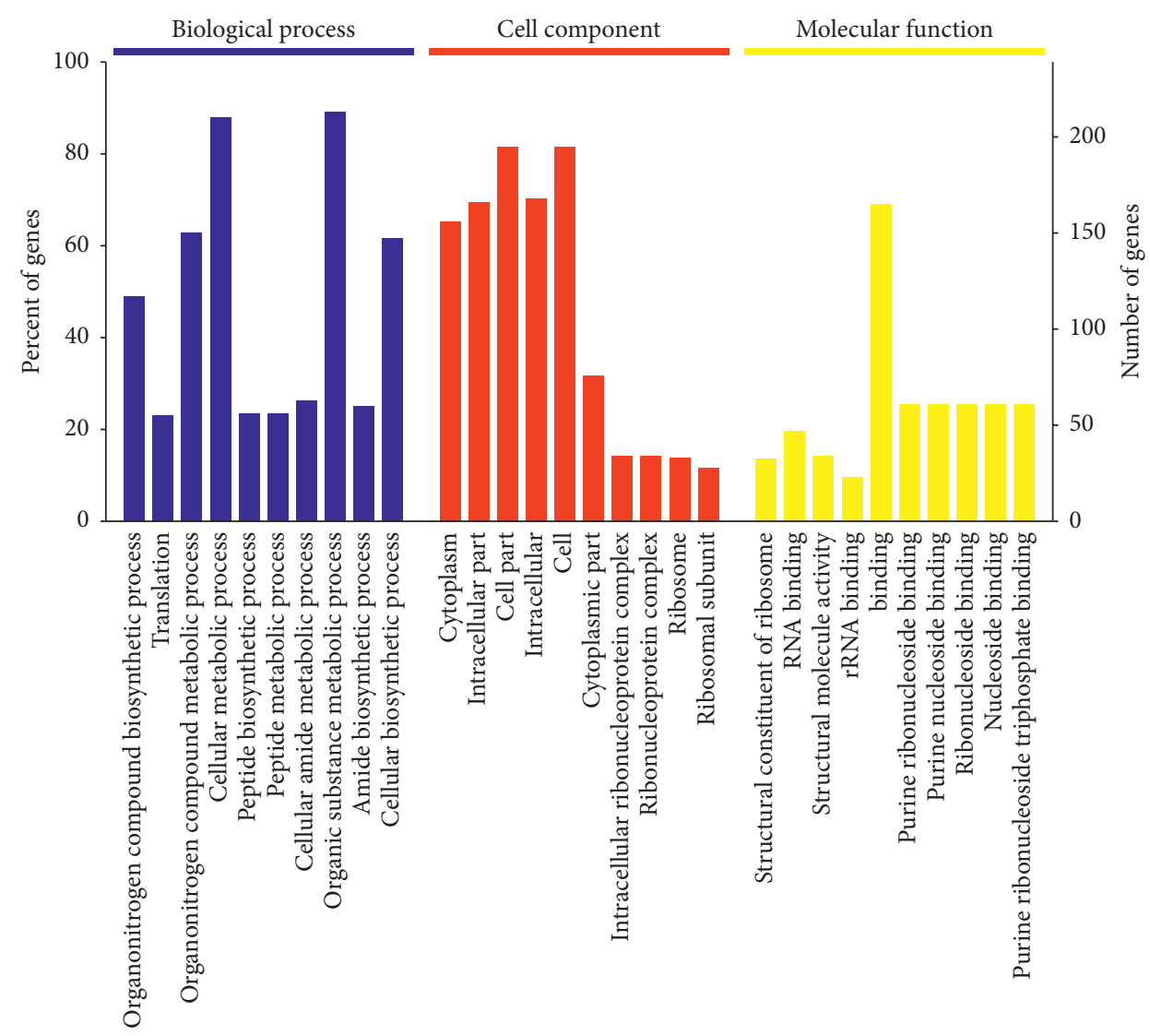

Figure 2: Gene Ontology (GO) enrichment analysis of differentially expressed proteins (S. putrefaciens cultivated at $4^{\circ} \mathrm{C}$ and $30^{\circ} \mathrm{C}$, respectively. $X$-axis represented each GO term; $Y$-axis represented the number of differentially expressed proteins in each category).

organisms. It plays a very important role, especially at the end of the catabolic glycolytic pathway, it is a key glycolytic enzyme, and its main role is to catalyze the dehydration of 2phosphate-d-glycerol (2-PGA) to produce phosphoenolpyruvate (PEP). In the presence of magnesium ions, it provides energy for organisms, so it is an important energy obtaining way for cells [33]. The upregulation of PGK and enolase was accompanied by the increase of glycolysis rate, which indicates the accumulation of pyruvate.

3.8. RPs. As mentioned above, RPs are one of the most abundant proteins. The effect of cold stress significantly increased their expression (Table 1), indicating their important role in the response to cold stress. Cold stress made the structure of ribosome subunits [34] incomplete, which stalled the translation process and reduced the number of polymers, but this reduction was temporary, accompanied by an increase in the number of a single 70 ribosome and 50 and 30 subunits [15]. Consistent with this, quantities of RPs increased when $S$. putrefaciens was cultivated at $4^{\circ} \mathrm{C}$ in the current research. For L. monocytogenes strains, the strongest and most active genomes are associated with ribosomal genes under cold stress [35]. We observed that nearly all of $30 \mathrm{~S}$ and 50S RPs were upregulated, including those encoded by rpl, rps, and rpm. The RPs themself adapt to the new stress conditions [36]. In vitro experiments showed that the $E$. coli translation apparatus in the cold environment can preferentially act on mRNAs from coldinduced genes [37]. The drop in temperature reduces cell membrane fluidity at the cellular level, and the active transport and secretion of proteins are also affected. The role of RNA helicase in different desiccants was studied. Helicase helps to unlock the secondary structure of RNA so that efficient transcription and translation processes can be achieved under cold stress [38]. Some studies on coldloving and mesothermal prokaryotes have shown that external ribonuclease and helicase (dead box protein) have this effect; chaperonin proteins have important roles in RNA degradation, nucleotide excision repair pathways, and cold adaptation [39]. There was evidence that RNA degradation under cold stress helps the cells to adapt its RNA metabolism for subsequent growth under cold stress [40]. With the stability of the secondary structure of DNA and RNA, in the case of reduced transcription and translation efficiency and low protein folding efficiency, RPs need to adapt to cold stress in order to function normally [41]. RPs are responsible for ribosome biogenesis and protein translation and play important roles in controlling cell growth, division, and development [42]. In the current research, $47 \mathrm{PRs}$ were identified as being upregulated. The kinetic properties of RPs are different at $4^{\circ} \mathrm{C}$ than at $30^{\circ} \mathrm{C}$, and a large increase in ribosome proteins may lead to the improvement of translation efficiency. Upregulated RPs 


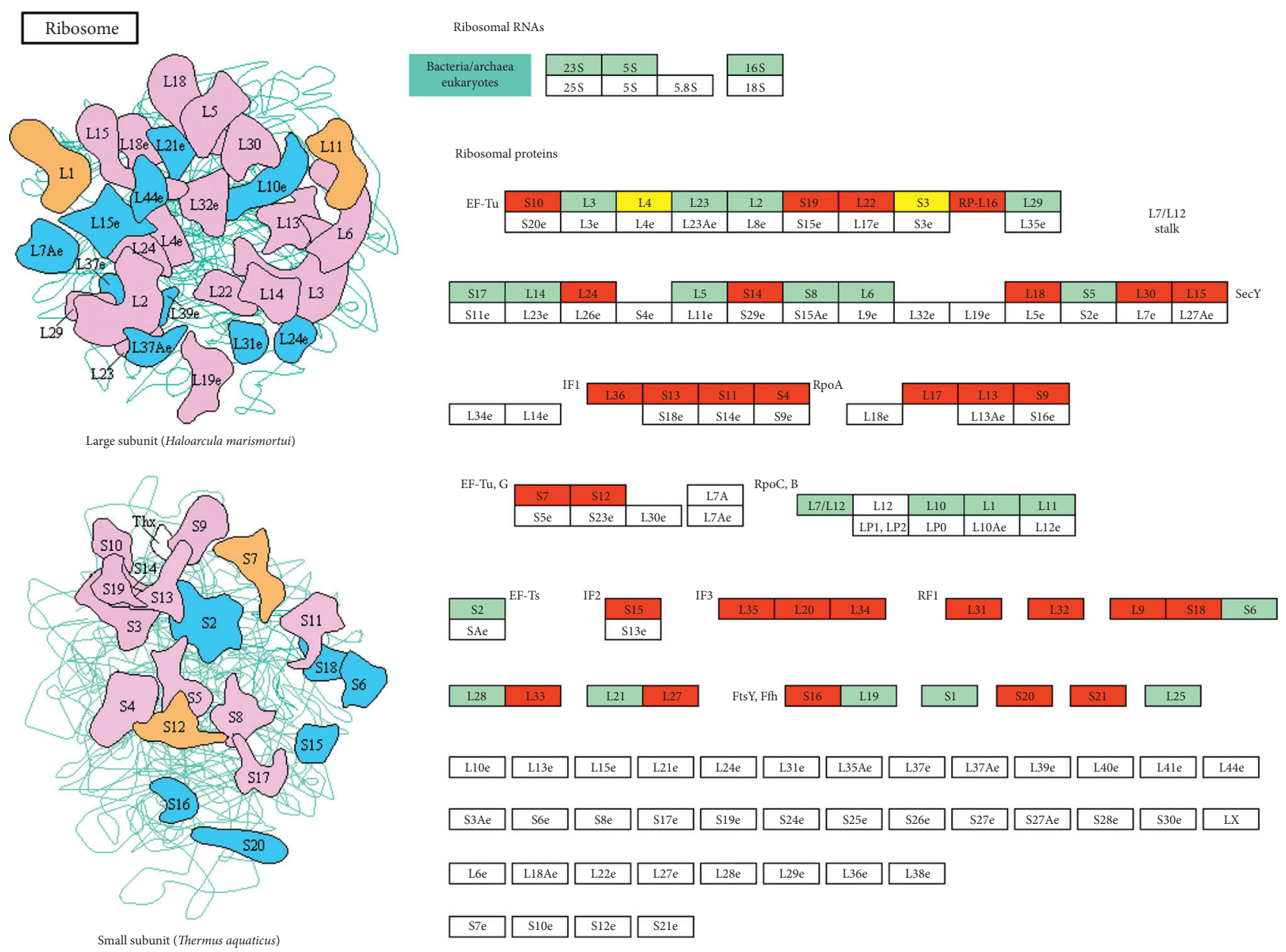

FIGURE 3: Schematic representation of the differentially expressed proteins involved in the ribosome pathway. The red boxes indicate the unregulated proteins, and the green boxes indicate the downregulated proteins.

under cold stress could enhance the appropriate translation or function of ribosome assembly in response to growth requirements. Under this circumstance, ribosomes that are more active under cold stress might be very important for S. putrefaciens under cold stress.

3.9. Translation. In the current study, several factors are upregulated under low temperature stress, such as proteins involved in translation (such as initiation factors IF-2 and extension factors), chaperones involved in protein folding, and proteins involved in transcription (such as DNA-directed RNA polymerase) found in Streptococcus putrefaciens. This shows that $S$. putrefaciens entered a stabilized phase, which is distinct from the state upon cold shock [15]. In the case of elongation factors, GreA, EF-P, and EF-Ts were upregulated. All were produced at a high level in S. putrefaciens under cold stress, indicating that protein synthesis was maintained to live under cold stress. The transcript cleavage factor, GreA, interacts with the RNAP secondary channel and stimulates the intrinsic transcript cleavage activity of RNAP for the removal of the aberrant RNA $3^{\prime}$ ends. Therefore, polymerization activity can be restarted from the end of a cleaved RNA allowing transcription to resume [43]. GreA is essential for the survival of bacteria under stress [44] and it can facilitate RecBCDmediated resection and inhibits RecA, which plays an important role in impeding DNA break repair in E. coli [45], indicating the role of GreA in adapting to the stressful environments. The eukaryotic and archaea extension factor $5 \mathrm{~A}$ (E/AEF-5A) and its prokaryotic bacterial translation extension factor $\mathrm{P}$ (EF-P) would slow the ribosome stagnation. The L-type EF-P is also composed of three bucket domains. Ef-p binds to the polyproline-stalled ribosomes between the peptide-TRNA binding site ( $\mathrm{P}$ site) and the exiting tRNA ( $E$ site) and stimulates the formation of peptide bonds by stabilizing the CCA end of prolyl-TRNA at $\mathrm{P}$ site. During translation elongation, the ribosome, with the help of translation elongation factors EF-G, EF-TU, and EFTS, binds the corresponding amino acid of each codon to the growing polypeptide chain and drives along the coding sequence of the mRNA. Ef-ts are involved in protein synthesis and translation extension, and their expression is increased [46-49].

3.10. Lipid Transport and Metabolism. The effect of temperature on bacterial membrane lipids has been extensively studied $[50,51]$. Bacteria adapt their membranes to lower the phase-transition temperature below which their membrane 


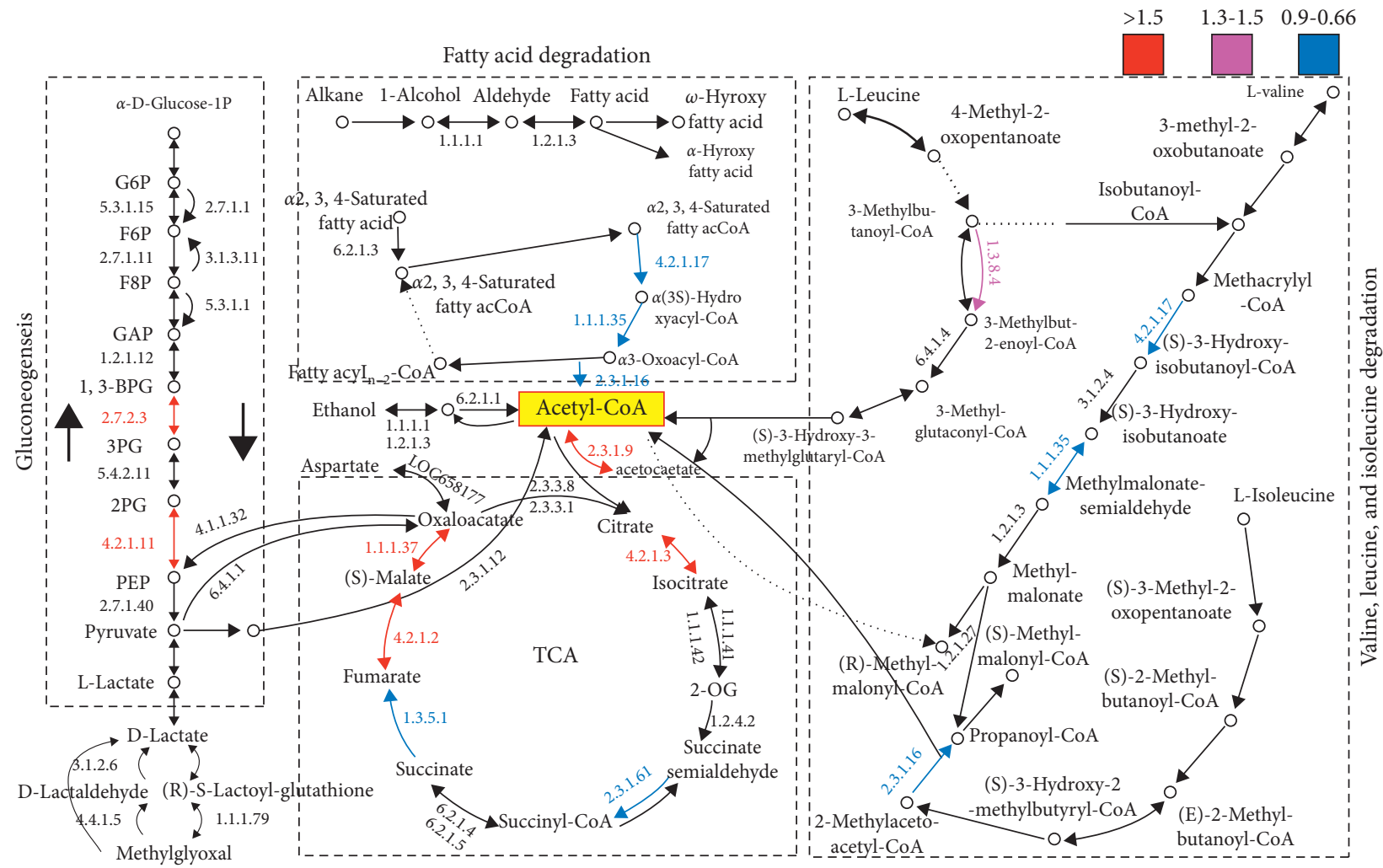

Figure 4: The metabolism pathway of the main energy sources. Different colors indicate the ranges of the fold change (cultivated at $4^{\circ} \mathrm{C} /$ cultivated at $30^{\circ} \mathrm{C}$ ) values.

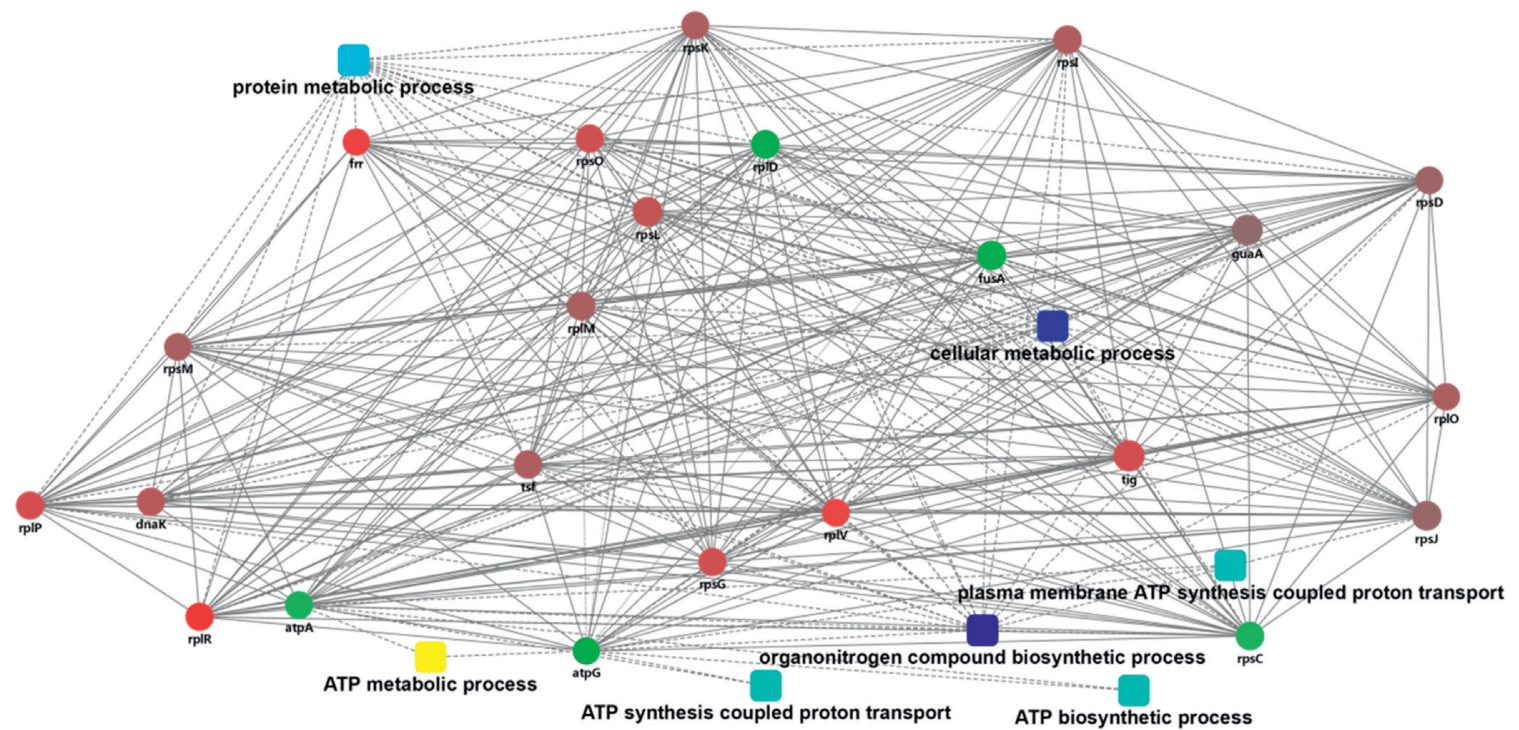

Figure 5: PPI network: significantly upregulated differentially expressed proteins of $S$. putrefaciens cultivated at $4^{\circ} \mathrm{C}$ and $30^{\circ} \mathrm{C}$, respectively. The proteins upregulated in $S$. putrefaciens are colored in a gradient color from white to red, $1.52 \leq \mathrm{FC} \leq 6.36$.

changes from a "fluid" (liquid-crystalline) to a "rigid" phase to maintain sufficient membrane fluidity under cold stress $[52,53]$. In the current research, 13 proteins (5 downregulated and 8 upregulated) were associated with lipid transport and metabolism in S. putrefaciens under cold stress. PlsY, lipB, fadR, fadI, and lpxD related to the lipid transport and metabolism were downregulated in
S. putrefaciens under cold stress. FadR regulatory protein acts as a regulator controlling bacterial lipid metabolism by inhibiting the fatty acid degradation (fad) system and activating the synthesis of unsaturated fatty acids [54]. In E. coli, FadR is a key gene for the synthesis of unsaturated fatty acids and positively regulates fabA and fabB. However, the FadR in S. putrefaciens under cold stress only regulates 
fabA fatty acid synthesis gene and the fabB protein did not change significantly, which was similar to the result of Yang et al. [54]. Fatty acid degradation occurs through the wellcharacterized $\beta$-oxidation cycle and produces acetyl-CoA, which is further metabolized for energy and precursors of cellular biosynthesis [55]. Acyl-CoA dehydrogenases could catalyze the initial steps in fatty acid $\beta$-oxidation. The longchain fatty acyl-CoA ligase could activate free fatty acids to acyl-CoA thioesters and DE proteins related to lipid synthesis including ketoacyl-ACP synthase III (FabH), which was upregulated under cold stress, which shows the protein expression in S. putrefaciens involved in fatty acid elongation and plays a critical role in maintaining the fluidity of membrane [56]. In some research studies, the FabH enzyme of $L$. monocytogenes prefers 2-methylbutyryl-CoA as the precursor of odd-numbered anteiso fatty acids under cold stress and increases the synthesis of anteiso fatty acids [57].

\section{Conclusions}

The ability to canvass a high proportion of the expressed proteome and define quantitatively large or small changes in protein abundance with strict statistical rigour has provided a strong view of $S$. putrefaciens under cold stress. The proteomics provided functional evidence supporting the importance of specific functional classes of genes that were identified as genomic markers of cold adaptation (e.g., energy metabolism). The quantitative analyses particularly showed the factor in S. putrefaciens under cold stress and the study identified specific pathways that were linked to the cold stress environment. The study provides a platform for comparative analyses of cold adaptation of other bacteria.

\section{Data Availability}

The data used to support the findings of this study are available from the corresponding author upon request.

\section{Conflicts of Interest}

The authors declare that they have no conflicts of interest.

\section{Acknowledgments}

This research was financially supported by the National Natural Science Foundation of China (grant numbers 31972142 and 31571914).

\section{References}

[1] H. E. Ramirez-Guerra, F. J. Castillo-Yanez, E. A. MontanoCota et al., "Protective effect of an edible tomato plant extract/ chitosan coating on the quality and shelf life of sierra fish fillets," Journal of Chemistry, vol. 2018, Article ID 2436045 , 6 pages, 2018.

[2] M. Sterniša, F. Bucar, O. Kunert, and S. Smole Možina, "Targeting fish spoilers Pseudomonas and Shewanella with oregano and nettle extracts," International Journal of Food Microbiology, vol. 328, Article ID 108664, 2020.

[3] R. Mabuchi, M. Adachi, A. Ishimaru, H. Zhao, H. Kikutani, and S. Tanimoto, "Changes in metabolic profiles of yellowtail
(Seriola quinqueradiata) muscle during cold storage as a freshness evaluation tool based on GC-MS metabolomics," Foods, vol. 8, no. 10, p. 511, 2019.

[4] S. Fang, Q. Zhou, Y. Hu, F. Liu, J. Mei, and J. Xie, "Antimicrobial carvacrol incorporated in flaxseed gum-sodium alginate active films to improve the quality attributes of Chinese sea bass (Lateolabrax maculatus) during cold storage," Molecules, vol. 24, no. 18, p. 3292, 2019.

[5] P. Li, Z. Chen, M. Tan, J. Mei, and J. Xie, "Evaluation of weakly acidic electrolyzed water and modified atmosphere packaging on the shelf life and quality of farmed puffer fish (Takifugu obscurus) during cold storage," Journal of Food Safety, vol. 40, Article ID e12773, 2020.

[6] J. Yan and J. Xie, "Comparative proteome analysis of Shewanella putrefaciens WS13 mature biofilm under cold stress," Front. Microbiol, vol. 11, p. 1225, 2020.

[7] X. Gao, W. Liu, J. Mei, and J. Xie, "Quantitative analysis of cold stress inducing lipidomic changes in Shewanella putrefaciens using UHPLC-ESI-MS/MS," Molecules, vol. 24, no. 24, p. 4609, 2019.

[8] M. P. Tribelli and I. N. López, "Reporting key features in coldadapted bacteria," Life, vol. 8, 2018.

[9] L. Garcia-Descalzo, A. Alcazar, F. Baqueroand, and C. Cid, "Biotechnological applications of cold-adapted bacteria," in Extremophiles, pp. 159-174, Wiley, New York, NY, USA, 2012.

[10] N. Hassan, A. M. Anesio, M. Rafiq et al., "Temperature driven membrane lipid adaptation in glacial psychrophilic bacteria," Front. Microbiol, vol. 11, p. 824, 2020.

[11] R. A. Baraúna, D. Y. Freitas, J. C. Pinheiro, A. R. C. Folador, and A. A. Silva, "A proteomic perspective on the bacterial adaptation to cold: integrating OMICs data of the psychrotrophic bacterium exiguobacterium antarcticum B7," Proteomes, vol. 5, no. 9, 2017.

[12] T. Yu, R. Keto-Timonen, X. Jiang, J.-P. Virtanen, and H. Korkeala, "Insights into the phylogeny and evolution of cold shock proteins: from Enteropathogenic Yersinia and Escherichia coli to Eubacteria," International Journal of Molecular Sciences, vol. 20, no. 16, p. 4059, 2019.

[13] X. Chen, L. Li, F. Yang, J. Wu, and S. Wang, "Effects of gelatinbased antifreeze peptides on cell viability and oxidant stress of Streptococcus thermophilus during cold stage," Food Chem. Toxicol, vol. 136, Article ID 111056, 2020.

[14] A. Hamdan, "Ecological significance and potential industrial application," South African Journal of Science, vol. 114, no. 5/ 6, Article ID 2017-0254, 2018.

[15] J. Jia, Y. Chen, Y. Jiang et al., "Proteomic analysis of Vibrio metschnikovii under cold stress using a quadrupole Orbitrap mass spectrometer," Research in Microbiology, vol. 166, no. 8, pp. 618-625, 2015.

[16] C. Ma, W. Wang, Y. Wang et al., “TMT-labeled quantitative proteomic analyses on the longissimus dorsi to identify the proteins underlying intramuscular fat content in pigs," Journal of Proteomics, vol. 213, Article ID 103630, 2020.

[17] J. Zecha, S. Satpathy, T. Kanashova et al., "TMT labeling for the masses: a robust and cost-efficient, in-solution labeling approach," Molecular \& Cellular Proteomics, vol. 18, no. 7, pp. 1468-1478, 2019.

[18] W. Ma, J. Jia, X. Huang et al., "Stable isotope labelling by amino acids in cell culture (SILAC) applied to quantitative proteomics of Edwardsiella tarda ATCC 15947 under prolonged cold stress," Microbial Pathogenesis, vol. 125, pp. 12$19,2018$.

[19] C. Hou, D. Guo, X. Yu, S. Wang, and T. Liu, “TMT-based proteomics analysis of the anti-hepatocellular carcinoma 
effect of combined dihydroartemisinin and sorafenib," Biomed. Pharmacother, vol. 126, Article ID 109862, 2020.

[20] Y.-H. Han, W.-Z. Liu, Y.-Z. Shi, L.-Q. Lu, S.-D. Xiao, and Q.-H. Zhang, "Gene expression profile of helicobacter pylori in response to growth temperature variation," The Journal of Microbiology, vol. 47, no. 4, pp. 455-465, 2009.

[21] M. K. Thompson, M. F. Rojas-Duran, P. Gangaramani, and W. V. Gilbert, "The ribosomal protein Asc1/RACK1 is required for efficient translation of short mRNAs," eLife, vol. 5, Article ID e11154, 2016.

[22] Z. Xinxin, Y. Shuang, Z. Xunming, W. Shang, Z. Juhong, and $\mathrm{X}$. Jinghui, "TMT-Based quantitative proteomic profiling of overwintering Lissorhoptrus oryzophilus," Frontiers in Physiology, vol. 10, p. 1623, 2020.

[23] P.-F. Liu, Y. Xia, X.-T. Hua et al., "Quantitative proteomic analysis in serum of Takifugu rubripes infected with Cryptocaryon irritans," Fish \& Shellfish Immunology, vol. 104, pp. 213-221, 2020.

[24] X. C. Zhang, J. Xie, and J. Mei, "Analysis of proteins associated with quality deterioration of grouper fillets based on TMT quantitative proteomics during refrigerated storage," Molecules, vol. 24, no. 14, p. 2641, 2019.

[25] L. Yarzábal, Antarctic psychrophilic microorganisms and biotechnology: history, current trends, applications, and challenges Microbial Models: From Environmental to Industrial Sustainability, S. Castro-Sowinski, Ed., vol. 5, pp. 83-118, Springer, Singapore, 2016.

[26] I. Bharudin, M. F. Abu Bakar, N. H. F. Hashim et al., "Unravelling the adaptation strategies employed by Glaciozyma antarctica PI12 on Antarctic sea ice," Marine Environmental Research, vol. 137, pp. 169-176, 2018.

[27] P. Buzzini, E. Branda, M. Goretti, and B. Turchetti, "Psychrophilic yeasts from worldwide glacial habitats: diversity, adaptation strategies and biotechnological potential," FEMS Microbiology Ecology, vol. 82, no. 2, pp. 217-241, 2012.

[28] G. Cacace, M. F. Mazzeo, A. Sorrentino, V. Spada, A. Malorni, and R. A. Siciliano, "Proteomics for the elucidation of cold adaptation mechanisms in Listeria monocytogenes," Journal of Proteomics, vol. 73, no. 10, pp. 2021-2030, 2010.

[29] D. P. Blagojevic, G. Gruborlajsic, and M. B. Spasic, "Cold defence responses the role of oxidative stress," Frontiers in Bioscience, vol. S3, no. 2, pp. 416-427, 2011.

[30] Q.-L. Sun, Y.-Y. Sun, J. Zhang et al., "High temperature-induced proteomic and metabolomic profiles of a thermophilic Bacillus manusensis isolated from the deep-sea hydrothermal field of Manus Basin," Journal of Proteomics, vol. 203, Article ID 103380, 2019.

[31] M. Wolf, T. Müller, T. Dandekar, and J. D. Pollack, "Phylogeny of Firmicutes with special reference to Mycoplasma (Mollicutes) as inferred from phosphoglycerate kinase amino acid sequence data," International Journal of Systematic and Evolutionary Microbiology, vol. 54, no. 3, pp. 871-875, 2004.

[32] J. D. Pollack, Q. Li, and D. K. Pearl, “Taxonomic utility of a phylogenetic analysis of phosphoglycerate kinase proteins of Archaea, Bacteria, and Eukaryota: insights by Bayesian analyses," Molecular Phylogenetics and Evolution, vol. 35, no. 2, pp. 420-430, 2005.

[33] H. Li, Y. Huang, J. Wang et al., "Molecular and biochemical characterization of enolase from Dermanyssus gallinae," Gene, vol. 756, Article ID 144911, 2020.

[34] T. Tasara and R. Stephan, "Cold stress tolerance of Listeria monocytogenes: a review of molecular adaptive mechanisms and food safety implications," Journal of Food Protection, vol. 69, no. 6, pp. 1473-1484, 2006.
[35] J. Durack, T. Ross, and J. Bowman, "Characterisation of the transcriptomes of genetically diverse Listeria monocytogenes exposed to hyperosmotic and low temperature conditions reveal global stress-adaptation mechanisms," PloS One, vol. 8, pp. 1-15, 2013.

[36] C. Barria, M. Malecki, and C. M. Arraiano, "Bacterial adaptation to cold," Microbiology, vol. 159, no. 12, pp. 2437-2443, 2013.

[37] A. M. Giuliodori, A. Brandi, C. Gualerzi, and C. Pon, "Preferential translation of cold-shock mRNAs during cold adaptation," RNA, vol. 10, no. 2, pp. 265-276, 2004.

[38] F. Piette, C. Struvay, and G. Feller, "The protein folding challenge in psychrophiles: facts and current issues," Environmental Microbiology, vol. 13, no. 8, pp. 1924-1933, 2011.

[39] G. Cartier, F. Lorieux, F. Allemand, M. Dreyfus, and T. Bizebard, "Cold adaptation in DEAD-box proteins," Biochemistry, vol. 49, no. 12, pp. 2636-2646, 2010.

[40] A.-F. Ghobakhlou, A. Johnston, L. Harris, H. Antoun, and S. Laberge, "Microarray transcriptional profiling of Arctic Mesorhizobium strain N33 at low temperature provides insights into cold adaption strategies," BMC Genomics, vol. 16, p. $383,2015$.

[41] R. Keto-Timonen, N. Hietala, E. Palonen, A. Hakakorpi, M. Lindström, and H. Korkeala, "Cold shock proteins: a minireview with special emphasis on csp-family of Enteropathogenicyersinia," Frontiers in Microbiology, vol. 7, p. 1151, 2016.

[42] K. Jastrzebski, K. M. Hannan, E. B. Tchoubrieva, R. D. Hannan, and R. B. Pearson, "Coordinate regulation of ribosome biogenesis and function by the ribosomal protein S6 kinase, a key mediator of mTOR function," Growth Factors, vol. 25, no. 4, pp. 209-226, 2007.

[43] S. Feng, Y. Liu, W. Liang et al., "Involvement of transcription elongation factor GreA in Mycobacterium viability, antibiotic susceptibility, and intracellular fitness," Frontiers in Microbiology, vol. 11, p. 413, 2020.

[44] R. K. Jha, S. Udupa, A. K. Rai et al., "Conditional downregulation of GreA impacts expression of rRNA and transcription factors, affecting Mycobacterium smegmatis survival," Scientific Reports, vol. 10, p. 5802, 2020.

[45] P. Sivaramakrishnan, L. A. Sepúlveda, J. A. Halliday et al., "The transcription fidelity factor GreA impedes DNA break repair," Nature, vol. 550, no. 7675, pp. 214-218, 2017.

[46] R. Krafczyk, J. Macošek, P. K. A. Jagtap et al., "Structural basis for earp-mediated arginine glycosylation of translation elongation factor EF-P,” mBio, vol. 8, no. 5, pp. e01412-01417, 2017.

[47] K. Hanawa-Suetsugu, S.-I. Sekine, H. Sakai et al., "Crystal structure of elongation factor P from Thermus thermophilus HB8," Proceedings of the National Academy of Sciences, vol. 101, no. 26, pp. 9595-9600, 2004.

[48] N. Tiller and R. Bock, "The translational apparatus of plastids and its role in plant development," Molecular Plant, vol. 7, no. 7, pp. 1105-1120, 2014.

[49] A. McLeod, M. Zagorec, M.-C. Champomier-Vergès, K. Naterstad, and L. Axelsson, "Primary metabolism in Lactobacillus sakei food isolates by proteomic analysis," BMC Microbiology, vol. 10, no. 1, p. 120, 2010.

[50] G. Seydlova, J. Beranova, I. Bibova et al., "The extent of the temperature-induced membrane remodeling in two closely relatedBordetellaspecies reflects their adaptation to diverse environmental niches," Journal of Biological Chemistry, vol. 292, no. 19, pp. 8048-8058, 2017. 
[51] M. M. Alreshidi, R. H. Dunstan, M. M. Macdonald, N. D. Smith, J. Gottfries, and T. K. Roberts, "Metabolomic and proteomic responses of Staphylococcus aureus to prolonged cold stress," Journal of Proteomics, vol. 121, pp. 44-55, 2015.

[52] N. J. Bale, W. I. C. Rijpstra, D. X. Sahonero-Canavesi et al., "Fatty acid and hopanoid adaption to cold in the methanotroph Methylovulum psychrotolerans," Frontiers in Microbiology, vol. 10, p. 589, 2019.

[53] M. F. Siliakus, J. Van Der Oost, and S. W. M. Kengen, "Adaptations of archaeal and bacterial membranes to variations in temperature, $\mathrm{pH}$ and pressure," Extremophiles, vol. 21, no. 4, pp. 651-670, 2017.

[54] S.-P. Yang, J. Xie, Y. Cheng, Z. Zhang, Y. Zhao, and Y.-F. Qian, "Response of Shewanella putrefaciens to low temperature regulated by membrane fluidity and fatty acid metabolism," Lebensmittel-Wissenschaft \& Technologie, vol. 117, Article ID 108638, 2020.

[55] S. Jia, H. Hong, Q. Yang et al., "TMT-based proteomic analysis of the fish-borne spoiler Pseudomonas psychrophila subjected to chitosan oligosaccharides in fish juice system," Food Microbiology, vol. 90, Article ID 103494, 2020.

[56] Y. Yoon, H. Lee, S. Lee, S. Kim, and K.-H. Choi, "Membrane fluidity-related adaptive response mechanisms of foodborne bacterial pathogens under environmental stresses," Food Research International, vol. 72, pp. 25-36, 2015.

[57] A. K. Singh, Y.-M. Zhang, K. Zhu et al., "FabH selectivity for anteiso branched-chain fatty acid precursors in low-temperature adaptation inListeria monocytogenes," FEMS Microbiology Letters, vol. 301, no. 2, pp. 188-192, 2009. 